\title{
Polymer heterogeneity in waterborne coatings
}

\author{
Ad Overbeek
}

(C) The Author(s) 2009. This article is published with open access at Springerlink.com

\begin{abstract}
An overview is presented of the progress in understanding polymer heterogeneity over the last 20 years and how this has contributed to the improvement of coatings. Solvent-based polymers are homogeneous in nature, since all polymeric materials tend to be dissolved in the same solvent mixture. This is different for most waterborne polymers, which tend to be present in a compartmentalized way. Most polymeric materials are present in particles, which are separated by the continuous aqueous phase. This gives excellent opportunities to create particle morphologies that form the basis for the film morphology after drying of the coating. This article gives an overview of the various types of heterogeneity which are accessible in waterborne polymers and will show how heterogeneity in the polymer can contribute to the solution of several persistent problems of the coating industry.
\end{abstract}

Keywords Coating, Heterogeneous, Waterborne, Gloss, Adhesion, Nano-structured, Hybrid

\section{Introduction}

The coatings world of today is putting high demands on performance in a period where sustainability, cost, environment, safety, and health aspects are high on the priority list of both industry and society. Many contradictory requirements like low volatile organic compound (VOC) with good hardness, solvent free with good adhesion to plastics, and combinations of

This paper was presented as the Mattiello Memorial Lecture at the 2009 CoatingsTech Conference, sponsored by NPCA/FSCT, April 28-29, 2009, in Indianapolis, IN.

A. Overbeek $(\bowtie)$

DSM NeoResins, Waalwijk, The Netherlands

e-mail: ad.overbeek@dsm.com nonblocking with high elasticity demand for innovations.

To make progress against these demanding targets, we can take nature as an example and also learn from the polymer alloy developments of the last decades. Both apply the concept of heterogeneity to create new and improved materials to fulfill a wide range of functions. This article gives an overview of the different forms of polymer heterogeneity, discusses its principles, and elucidates the relationship of composition, structure, and functions for a number of demanding coating applications. Based on these insights, future developments in waterborne coatings are envisaged.

\section{Different levels of heterogeneity}

Heterogeneity can express itself in many different forms. When more than one population of particles is present in a mixture or blend, they may differ in, for instance, their particle size distribution (PSD), hydrophobicity, glass transition temperature $\left(T_{\mathrm{g}}\right)$, molecular weight $(\mathrm{Mw})$, and/or polymer class.

Combining two different polymers of the same polymer class within one particle is a next level of control over heterogeneity that is often applied in addition polymers like acrylic dispersions.

In genuine hybrid particles, more than one polymer class is present per particle. The commercially most relevant examples of different polymer classes within one particle are the urethane acrylic and alkyd acrylic hybrids.

An even more advanced level of control over polymer heterogeneity can be attained by controlling the molecular build-up of each individual chain within a particle. Interesting examples of this group are the amphiphilic polymers, which organize themselves at the polymer-water interface.

The above-mentioned forms of heterogeneity will be described in more detail and specific examples of the 
relation between structure and properties in paints will be given in the "Experimental" section.

\section{More than one population of particles in the same system}

Aqueous polymer dispersions provide a considerable amount of design flexibility because of the ability to combine more than one population of particles in the same system. Blending of different waterborne polymer systems is a route which is readily available and this has been widely practiced. More advanced routes are now available to make these different populations of particles in situ. In this section, both methods will get attention and the advantages and disadvantages of both will be discussed.

\section{Heterogeneity in particle size}

A frequently applied tool to influence properties in aqueous polymeric dispersions ${ }^{1}$ is to combine different polymer populations with respect to particle size.

Most research on particle sizes in lattices has been focused on monomodal dispersions. Controlling PSD is, however, of significant practical importance, since it allows one to increase the solids content of polymeric dispersions and with this, the solids of the paint made from these dispersions.

The increased solids level increases the rate of drying, and will impact the rheological properties like flow out of brush marks and "distinctness of image" (DOI), and can be of use to improve the "brush drag" and the hiding power of paint.

Latex dispersions with a particle size of $80-120 \mathrm{~nm}$ can achieve a maximum solid content of about $45 \mathrm{wt} \%$. Larger monomodal particles will result in a higher solids content, and $400 \mathrm{~nm}$ particles can achieve a solids content up to about $60 \mathrm{wt} \%$. This difference is due to the contribution of the particle's electrical double layers to the hydrodynamic volume fractions of the dispersions, which is more pronounced for the smaller particles.

To illustrate the importance of a certain degree of heterogeneity in PSD of lattices, we take a closer look at the spatial arrangements of monodisperse particles at increasing solids content. An unwanted phenomenon sometimes observed with high solids monomodal particles is the phase transition from a random fluidlike arrangement of the particle dispersion to crystalline packing. For a monomodal distribution of hard spheres it has been established that random packing occurs until 49 vol. $\% .^{2}$ When the solids content is further increased, an fcc crystalline packing becomes more preferred because the system can gain free volume entropy. A randomly packed fluid-like hard sphere dispersion of 49 vol. \% coexists with an fccpacked dispersion with solids content of 54 vol.\% of hard spheres. ${ }^{3}$ Due to this packing behavior of dispersions with a monomodal particle size, sometimes two coexisting phases can be observed with different density. This phenomenon will in practice appear at a somewhat lower solids content, depending on the particle interactions and the thickness of the stabilizing layer around the particles.

From a coating perspective, two layers of different solids content are highly undesirable and this problem can be avoided by making use of particle populations of different size or of a single population of particles with a broader PSD: beyond a size polydispersity of about $10 \%$, the fluid-crystal phase transition does not take place anymore. ${ }^{4}$

Blends of particles of 80 and $450 \mathrm{~nm}$ allow the solids to be raised readily to $60 \mathrm{wt} \%$, which is explained by the fact that the small particles fit in the voids of the large particles. ${ }^{5}$ This way the overall void volume is minimized.

Kim and Luckham ${ }^{6}$ found the lowest elastic modulus for a 80/20 large/small ratio with the large particles being about 7 times larger than the small ones. A similar ratio gave the lowest water absorption and a decrease in minimum film-formation temperature (MFT). ${ }^{7}$

Polymodal distribution has been studied in depth ${ }^{8-10}$ and especially bimodal PSDs have been the focus of research by many groups. ${ }^{711}$

While blending of dispersions ${ }^{12}$ with a different particle size is the most common route to obtain the bimodality in particles size, in situ preparation has some intrinsic advantages, like a higher solids content, cutting out the blending step, and the ability to make complex systems without the necessity of using multiple reactors.

Due to these advantages several in situ routes have been investigated to produce these bimodal lattices. ${ }^{13-16}$ One of the most common routes utilized in emulsion polymerization is to first synthesize large particles, followed by a surfactant shot, which upon addition of additional monomers leads as a result of secondary nucleation to the formation of a second population of particles with significantly smaller diameter.

Alternatively, a low amount of small particle size seed can be added to a large particle size dispersion, after which additionally fed monomer polymerizes in both particles to result in an in situ-prepared bimodal PSD.

A very useful way to exploit bimodal particle size dispersions is by using the "surface enrichment" effect of small particles that becomes visible, when blending particles of different sizes. This is schematically represented in Fig. 1.

Figure 2 shows an scanning electron microscopy (SEM) photo of a film made from a dispersion with a bimodal PSD with a large/small ratio of $80 / 20$. The $20 \mathrm{wt} \%$ of small particles cover more than $50 \%$ of the surface of the coating, which supports the thesis of surface enrichment of small particles in a bimodal particle size dispersion. 


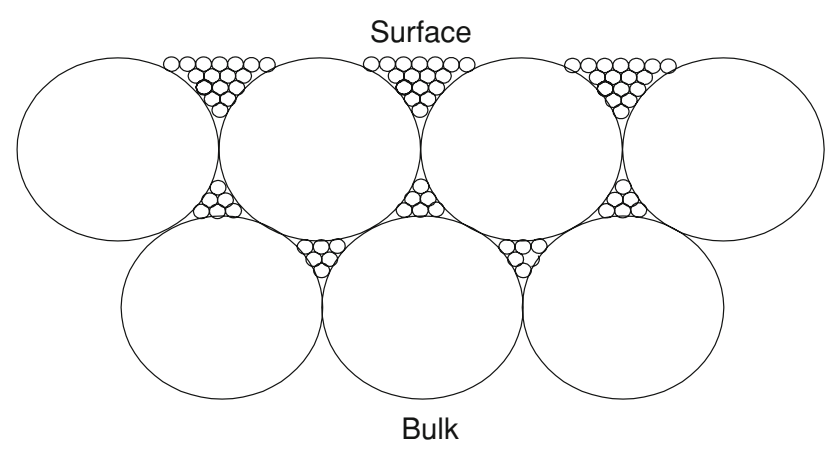

Fig. 1: Schematic representation of packing of particles with a bimodal distribution

This provides us with a very useful tool for dirt pickup reduction and for improving the early stackability of coatings.

The surface enrichment effect will be similar at the coating substrate interface, making this an interesting route to use adhesion promotion functionality in a more economical way.

Another benefit of polymeric dispersions with a bimodal PSD is the fast drying, due to the overall lower water content, which explains their use in road paints ${ }^{17}$ and industrial applications. ${ }^{7}$

\section{Heterogeneity in molecular weight}

Tomba et al. ${ }^{18}$ have combined low and high $\mathrm{Mw}$ compositions of methyl methacrylate/butyl acrylate with identical compositions to reduce VOC levels. This work makes use of the strong dependence of $T_{\mathrm{g}}$ on $\mathrm{Mw}$, where the $T_{\mathrm{g}}$ decreases progressively with reduction of the Mw below the entanglement Mw. The same composition is used for both Mw polymers to ensure a good miscibility on film formation.

The efficiency of the low Mw (oligomeric) latex particles as diffusion promoters for the high $\mathrm{Mw}$ polymer was studied and full miscibility was obtained within the usual time needed for film formation. This does show that these polymers are completely compatible.
An excellent example of the use of Mw heterogeneity is in pressure-sensitive adhesives and polymers for toner applications.

Another possibility is to combine polymers that are largely incompatible, and where the low Mw polymer, due to its decrease in $\mathrm{Mw}$, also becomes low in viscosity. This leads to very interesting properties like self stratification ${ }^{19,20}$ and improved open time, and the latter will further be described in the section "Heterogeneity in terms of polymer viscosity."

\section{Heterogeneity in hydrophilicity}

Low Mw high acid value polymers are well known in the printing ink industry, where resolubility on a press is one of the key properties. Combinations of low $\mathrm{Mw}$ high acid value and high Mw low acid value polymers ${ }^{21}$ were first used in ink and overprint varnish applications. The low Mw high acid value polymer provides stability to the system and is responsible for the resolubility characteristics, whereas the high $\mathrm{Mw}$ low acid value polymer improves properties like water resistance. This concept has found wide applicability in several coating applications, including anticorrosion primers, decorative paints, road paints, ${ }^{22}$ and industrial paints, where the low $\mathrm{Mw}$ part introduces overspray recyclability to the system. ${ }^{23}$

\section{Heterogeneity in glass transition temperature}

Combining particle populations in one system, which vary in glass transition temperature, gives useful properties which can be applied in many coatings applications.

The $T_{\mathrm{g}}$ of a latex is one of the main factors that determines its mechanical properties. ${ }^{24}$

To obtain a strong and resilient coating film, it is necessary that both the modulus of elasticity and the elongation are at a high level. ${ }^{25}$ Optimal enforcement of the film can therefore only occur when both properties are increased at the same time. ${ }^{26}$

Elongation can easily be increased by adjusting the hard/soft ratios in systems in which there is a continuous matrix of soft material. ${ }^{27}$ For the modulus of

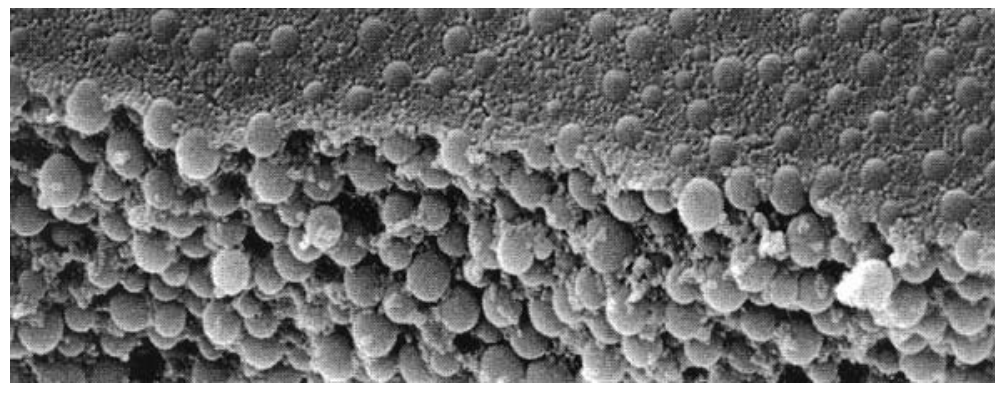

Fig. 2: Crosscut SEM of a bimodal PSD with a large/small ratio of $80 / 20$ 
elasticity to increase, it is necessary to reduce the mobility of the soft chains, either by chemical bonds, hydrogen bridging, ${ }^{28}$ and crystalline domains or by steric hindrance.

When hard particles are present in dispersed form in a soft matrix, these hard elements will restrict the mobility of the low $T_{\mathrm{g}}$ chains, thus improving properties like block resistance, tensile strength, hardness, scratch, and abrasion resistance which is further elucidated in the section "Influence of sequential polymerization on mechanical properties for highly elastic films."

The case where soft particles are present in dispersed form in a hard matrix is quite common in the plastic industry. A typical example is impact modifiers, where a soft core has a grafted hard shell around it to create the optimal situation for inhibiting crack propagation, where the desirable energy dissipation can occur to stop further crack propagation. In coatings, however, such hard and rigid compositions are seldom used.

The key for achieving optimal properties in blends, especially when a high toughness and modulus of elasticity is required, is a high-quality interface between both phases. ${ }^{29,30}$ When one of the two phases is glassy, the rate of entanglement formation becomes very low and one may want to rely on crosslinking chemistry or hydrogen bridging ${ }^{28}$ to improve properties.

An alternative way to create a strong interface is to make both phases in one particle, as will be described further in the section "More than one population of polymers within the same particle."

\section{Heterogeneity in terms of polymer viscosity}

The viscosity of the polymer is a parameter, which gives interesting options for controlling the rheology during the drying of the paint. ${ }^{31}$

A topic that has been on the wish list of many paint companies is to offer a waterborne paint to the market with similar open time to that of solvent-based alkyd paints.

Acrylic dispersions suffer from a too fast sintering of the particles, after which brushability is no longer possible. Alkyd emulsions have a different problem. On drying, phase inversion occurs, which in one published paper is believed to go through a lamellar structure. ${ }^{32}$

Due to this phase inversion, the coating suffers from a temporarily high viscosity, which makes the brush stick into the paint (Fig. 3).

Both types of rheology described above are inferior to that of solvent-based alkyds, when the paint is applied by brush. The challenge for brush-applied paints is to maintain a good flow of the coating in the early phases of drying. After 15-25 min, when "open time" is no longer required, the viscosity preferably increases quickly to maintain a reasonable drying time.

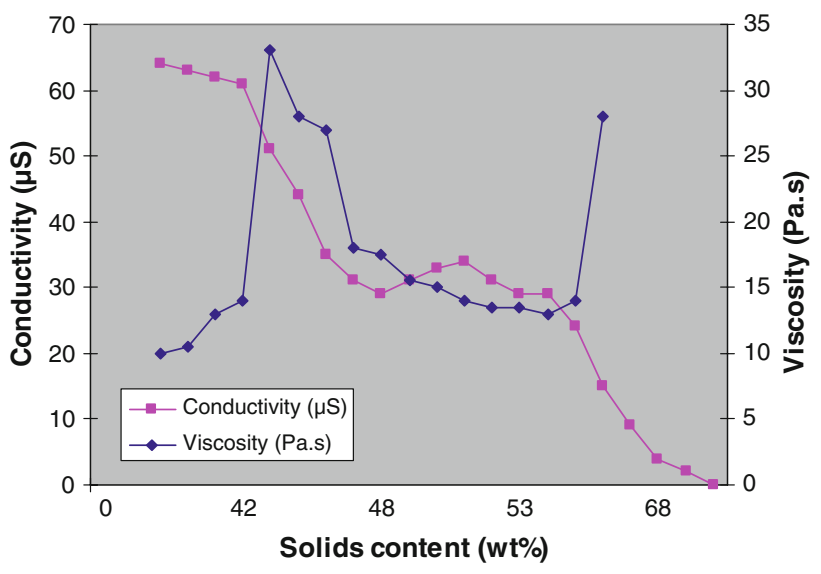

Fig. 3: Phase inversion of a fatty acid functional urethane oligomer, starting at low solids; increase in solids is obtained by blowing $\mathrm{N}_{2}$ over the sample surface ${ }^{31}$

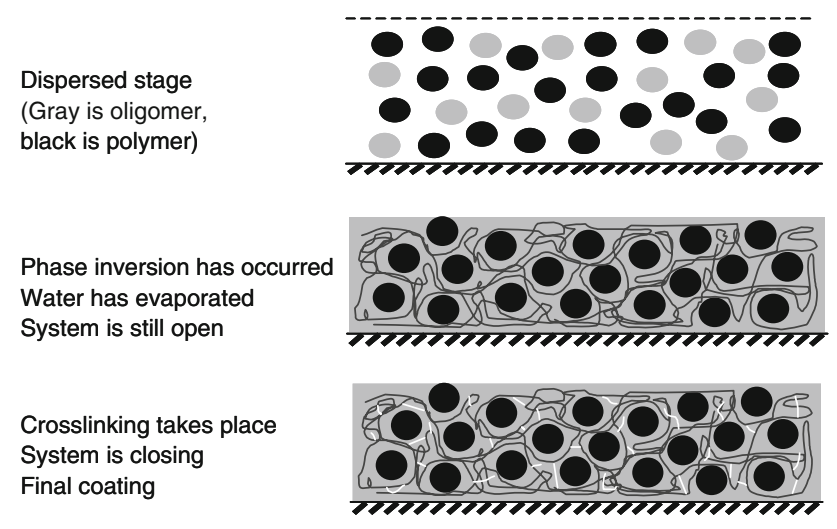

Fig. 4: Film formation of a waterborne system with improved open time

This preferred viscosity profile can be obtained by combining low-viscous oligomers with high Mw polymeric particles (Fig. 4). ${ }^{33,34}$

The oligomer needs to build up Mw to end up at the desired level of performance in a reasonable time frame. The crosslink mechanism for the oligomer should preferably result in a one pack system, contribute to the required low viscosity, and be economical, and for these reasons, autoxidation of fatty acid functionality seems to be the most appropriate crosslink mechanism.

It will be understood that there is still some yellowing due to the fatty acids being present in the oligomer and that hardness build-up is generally slower compared to pure acrylic dispersions. The fatty acid functionality contributes by lowering the viscosity as well as by introducing crosslink ability to the polymer.

In this case, there is heterogeneity in terms of $\mathrm{Mw}$, viscosity, polymer type, and often PSD as well.

To obtain an indication of the viscosity of the drying paint film, a "thin film analyzer" was used, ${ }^{35}$ which 


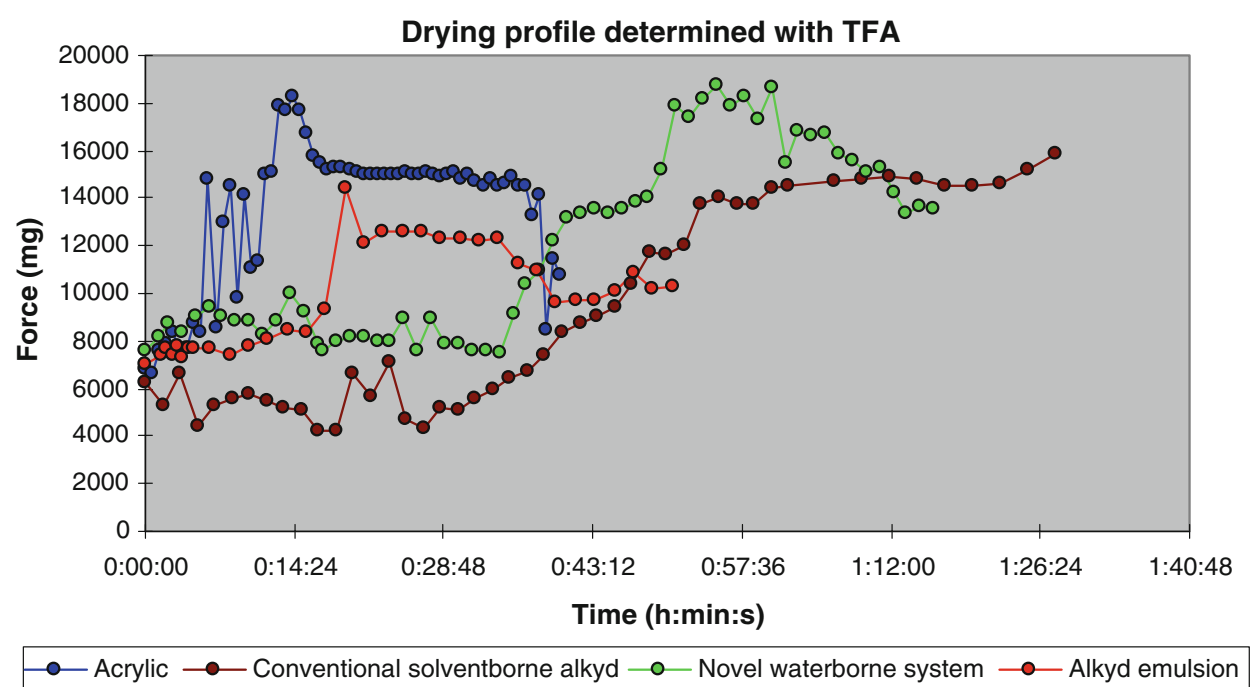

Fig. 5: Drying profile measured with a thin film analyzer

measures the force needed to pull a probe through a paint film. The magnitude of this force is directly related to the viscosity of the drying paint film. In Fig. 5, the development of thus measured "viscosity on drying" was compared for an acrylic dispersion, an alkyd emulsion, a solvent-based long oil alkyd, and the low-viscous oligomer/polymer combination.

In Fig. 5 it is clear that in the time frame of 3550 min after application, the viscosity of the oligomer/ polymer combination is visibly higher than that of the solvent-based alkyd. Although this does not negatively influence the open time of the paint, it does have a negative influence on the gloss level as will be further explained in sections "Amphiphilic polymers" and "Experimental" (DOI).

\section{Polymer class}

The combination of different polymer classes in one system has appealed to many researchers over the years due to the potential synergies that might be achieved.

\section{Blends of alkyds and acrylics}

The main drive to combine alkyds with acrylics has been the perceived synergy that might emerge from this combination.

Alkyds are for a large part based on renewable raw material, which is of interest from a "human footprint' or "cradle to cradle" point of view.

Alkyd emulsions can give films without any VOCs, and the general paint performance is at a very satisfactory level. Their disadvantages, however, lay in their tendency to yellow in time, ${ }^{36}$ the slow drying, and in outdoor applications, the slow but inevitable increase in brittleness and eventual cracking especially with varnishes.

Acrylics, on the other hand, usually require some coalescents for good film formation, dry very quickly, and aging of the paint films will hardly result in a change in mechanical properties or color.

There is a distinct difference in the film formation mechanism of alkyd emulsions compared to acrylics dispersions. Acrylics of high Mw go through a physical drying stage, including the sintering of particles and interdiffusion of chains and the formation of entanglements as the mechanism to build cohesive strength. Alkyd emulsions of low Mw, however, have been reported to go through a metastable state ${ }^{32}$ followed by phase inversion to form a water-in-oil emulsion. The cohesive strength of the film is subsequently built-up by a slow autoxidation process.

When aqueous blends of alkyds and acrylics are used in equal amounts, the low Mw alkyd will quickly become the continuous phase during the drying process. Although this results in void-free film formation, the suggestion that the alkyd component of alkyd/ acrylic blends can act as a coalescing agent for the acrylic and reduces the glass transition temperature of the acrylic particles by interdiffusion of alkyd molecules into the acrylic particles is unlikely to be correct. The interdiffusion rate would be slow compared to drying rate of the alkyd ${ }^{32}$ and indeed it is highly unlikely that there will be any interdiffusion at all due to the inherent incompatibility of the two polymer types.

This inherent incompatibility is the result of thermodynamic inhibition because the free energy of mixing of the two polymers is positive for most polymer combinations. ${ }^{37}$

Due to this incompatibility, gloss is often less than desired. Formation of a haze on film formation is a quite common phenomenon with these blends, which 
can be attributed to both the formation of aggregates of acrylic particles during the film formation process as well as to differences in refractive index of the alkyd and the acrylic.

Alkyd acrylic blends have found use in self-stratifying systems on wood ${ }^{19}$ stain-blocking systems, ${ }^{38}$ wood primers, and low VOC architectural paints. ${ }^{39}$

\section{Blends of urethanes with acrylics}

Dispersions of polyurethanes ${ }^{40}$ and polyacrylates are often combined due to their complementary properties. $^{41}$ Polyurethane dispersions offer high performance, especially in terms of mechanical properties like high tensile strength, abrasion resistance, chemical resistance, and good toughness. This makes them very useful for flooring applications and for furniture where abrasion and scratch resistance are needed.

The polyurethanes have also been used to reduce the VOC level of the acrylic dispersions and to improve the flexibility of the acrylics, especially in outdoor applications. Hydrogen bonding plays a vital role in the build-up of cohesive strength in blends containing polyurethane dispersions.

Coreactive dispersions are a special case of blends of dispersions of polyurethanes and acrylics. In a typical example, the polyurethane is semicarbazide functional and the acrylic contains carbonyl groups. ${ }^{42,43}$ These mixtures show a good storage stability without premature crosslinking, and synergistic properties have been reported, including flexibility at low temperature and a good abrasion resistance. ${ }^{44}$

\section{More than one population of polymers within the same particle ${ }^{45}$}

Another distinct type of heterogeneity is the situation in which each individual particle in an aqueous polymer dispersion contains more than one polymer. In the following sections, addition polymer/addition polymer combinations and addition polymer/condensation polymer combinations are discussed.

From traditional materials it is known that the nature and extent of bonding between the various phases critically determines the mechanical strength and other properties of the material. ${ }^{46}$ This is equally true for coating layers derived from nanostructured particles.

The continuous phase in coatings is preferably the most elastic phase, and the embedded harder dispersed phase will increase the modulus of elasticity or the resistance to elongation of the material. The increase in modulus is caused by hard domains restricting the reptation of the soft chains, provided a good interaction takes place between continuous and dispersed phase, to ensure proper stress transfer.
Examples of the influence of hard domains on the mechanical properties of composite particles can be found in the "Experimental" section.

\section{Sequentially produced free radical polymers}

Acrylic dispersions are the most common examples of this type of system in which there is more than one polymer composition present per particle. They are usually prepared through a sequential emulsion polymerization process.

Different morphologies have been found for particles made according to this process and numerous papers have been published to describe the factors controlling the ultimate particle morphology. Sundberg and coworkers have been particularly active in this field, and have developed a sophisticated treatment which takes into account both thermodynamic and kinetic aspects to predict particle morphology. ${ }^{47}$

Initial research emphasized the argument that the thermodynamically most preferred morphology will have the lowest total interfacial energy $G^{47-49}$ :

$G=\Sigma \gamma_{i j} A_{i j}$

where $A$ is the interfacial area and $\gamma$ is the interfacial energy between phases $i$ and $j$. Based on this equation, a core shell morphology is the equilibrium preferred morphology in a two-phase system if the phase which is polymerized second is significantly more hydrophilic than the first one. In practice, however, this does not always have to be the case, e.g., at high surfactant loadings, where differences between interfacial tensions of the polymer phases against water become less pronounced. In analogy to this, an inverted core shell is often the result if the second phase is more hydrophobic than the first one. In practice, however, thermodynamic equilibrium morphology is quite rare. The equilibrium situation is likely to be achieved during polymerization if the rate of diffusion of the growing polymer chain is faster than the polymerization rate. The most frequently occurring kinetically controlled morphology is more likely when polymerization rate is much faster than the phase separation.

When a first polymeric dispersion is used to polymerize a second composition, a number of factors will influence the final nanostructured morphology of the system. $^{50-54}$

The most relevant ones are the degree of radical penetration into the seed particle, which is dependant on the seed $T_{\mathrm{g}}{ }^{55}$ the difference between $T_{\mathrm{g}}$ and reaction temperature, the hydrophilicity of the composition, the level of compatibility, and the relative amount of both phases present. If radical penetration is possible, phase separation becomes important, since chains of the second polymer are formed throughout 
the first-stage polymer particles, creating chain entanglements and the opportunity for extensive polymer mixing. If radical penetration is highly limited, for instance when the $T_{\mathrm{g}}$ of the first phase is considerably above the temperature of polymerization of the second phase, the particle will build in layers and phase separation becomes irrelevant because the polymers are never given the opportunity for intimate mixing.

The phase consolidation is driven by thermodynamics and might occur by growth of domains by polymerization, coalescence of domains, and Ostwald ripening.

Nanostructured or sequentially polymerized acrylics have found wide use in the coating industry, in decorative paint, furniture, joinery, inks, adhesives, and many other application areas.

The different phases in sequentially polymerized lattices can vary in many aspects, including $T_{\mathrm{g}}$, Mw, hydrophilicity, and functional group concentration. Of particular interest for coatings are the polymers with more than one glass transition temperature. ${ }^{56}$

A composition which is polymerized sequentially, whereby the monomers are split to deliver a $T_{\mathrm{g}}$ difference, can give both a reduction in MFT and show a reduced thermoplasticity as well, when compared to the same composition which is polymerized as a one phase polymer ${ }^{57}$ (see Tables 2 and 3 ).

This feature makes sequential polymers with a $T_{\mathrm{g}}$ difference between both phases specifically useful for applications where fast drying and low VOC need to be combined.

\section{Urethane acrylic hybrids}

Combining urethanes with acrylics ${ }^{58-68}$ in a single particle is an example where one polymer acts as the stabilizer for a second polymer, and synergetic properties have been reported for this combination. ${ }^{69,70}$

Aqueous polyurethane dispersions have been around for a long time. They can be made by dissipating isocyanate functional prepolymers in water, followed by chain extension with polyamines. The viscosity for most polyurethane prepolymer compositions is too high to be processed and for this reason, inert solvent like, for instance, $N$-methylpyrrolidone is frequently used during the prepolymer synthesis.

This has been the leading technology for many years, until the environmental pressures in the mid-80s led to the development of several methods to reduce prepolymer viscosity without using $\mathrm{N}$-methylpyrrolidone, which contributes to VOC emission.

One alternative process makes use of a low-boiling point solvent, which is removed by distillation after the prepolymer is chain extended in water. The result is an almost solvent-free dispersion. This rather expensive process has a side effect: acetone, which is typically used in this process, interferes with the amine functional chain extender. This will have a suppressing effect on the Mw build-up of the polyurethane and often leads to reduced levels of resistance.

High Mw polyurethane dispersions with good resistances can be prepared without the negative effects of in-process solvents, by reducing the viscosity of the prepolymer through the addition of free radically polymerizable monomers. After dispersion of the prepolymer in water and subsequent chain extension, the monomers can be polymerized, thus giving a high $\mathrm{Mw}$ urethane acrylic hybrid dispersion.

When comparing these hybrids with the blend of a cosolvent-free urethane and an acrylic dispersion, it appears that much stronger films result from the hybrid particles. In particular, the mechanical properties of these hybrids are frequently superior when compared to the blend of urethane and acrylic dispersions with similar composition.

This is attributed to the formation of a strong interphase material, consisting of intimately mixed, interpenetrating network of urethane and acrylic polymer, which is formed during the synthesis of these hybrids. ${ }^{21}$

Coogan and coworkers ${ }^{71}$ quantitatively measured the amount of interface material in urethane acrylic hybrids and their corresponding blends by means of m-DSC.

The improved mechanical performance found could directly be attributed to the increased level of interface material present in the hybrid polymers, and AFM results show an improved dispersion of hard acrylic domains in a soft polyurethane matrix compared to the blends.

Another example of the relevance of interaction between both phases on mechanical properties is given by Guyot and coworkers. ${ }^{72}$ A urethane acrylic hybrid was prepared by a mini-emulsion polymerization route and compared to the same material made through a seeded emulsion route. The main difference was that the acid of the polyurethane was neutralized in the seeded route. The mini-emulsion route delivered the best mechanical properties which were explained by a better mixing of the corresponding polymers prepared in one step instead of two steps for the seeded emulsion route.

Due to their excellent mechanical properties and resistances to all kind of solvents and stains, these hybrids have found a wide use in areas where abrasion, scratch, and general resistances are required. Typical examples are coatings for parquet flooring and industrial wood.

\section{Saturated polyester acrylic hybrids}

Aqueous polyesters are preformed polymers dispersed in water, which limits their $\mathrm{Mw}$ due to viscosity restriction during the dispersion step. 


\section{Molecular weight}

When compared to polyurethanes, polyesters do not have the advantage of being chain extended during the dispersion step and hence have insufficient resistances at the relatively low Mws required for dispersion in water.

Unsaturated polyesters have been described which are grafted with an acrylic polymer in a subsequent mini-emulsion polymerization ${ }^{73}$ to build up Mw. Also, acryloyl functional polyesters have been used in this way. Both grafting reactions lead to crosslinked particles which can suffer from impaired coalescence on application. More common is the combination of polyester dispersions with external crosslinkers like polyisocyanates or melamines to reach the required performance level in the final coating.

\section{Colloid stabilization}

Polyesters are sensitive to hydrolysis, in particular the trimellitic anhydride-based polyesters or hydroxyl functional polyesters post functionalized with anhydrides to introduce carboxylic acid groups for stabilization. In these types of polyesters, the carboxylic acid group catalyzes the hydrolysis of the neighboring ester, also known as the anchimeric group effect. ${ }^{74,75}$

Surfactants have been used to mechanically disperse/stabilize the polyesters in water, at the expense of water resistance and adhesion caused by surfactant migration to the surfaces. Also, polyethylene glycols have been applied as building block to aid stabilization. $^{76}$

Sulphonate groups have been introduced to reduce the sensitivity to hydrolysis. They are effective in imparting water dispersibility at low levels ${ }^{77}$ without the need of cosolvents and in the absence of surfactants and volatile amines. Sulpho isophtalic acid is the most well-known building block to introduce sulphonate into polyesters, ${ }^{78}$ and good properties have been reported on gloss, hardness, flexibility, and solvent resistance. Moreover, the coatings are claimed to be water resistant, despite the presence of ionic sulphonate groups, which is attributed to the strong stabilization power of the sulphonate groups allowing good dispersions to be made at very low ionic group levels.

In polyester acrylic hybrid particles, it is common to use the polyester as stabilizing material during the acrylate polymerization. ${ }^{79}$ An alternative method is to incorporate the ionic groups in the acrylic backbone and graft the polyester and acrylate together, for instance, by a polycondensation route. ${ }^{80}$ This will give an ionic group in a hydrolytically insensitive environment and the polyester, which is more prone to hydrolysis, will be positioned in the core of the particle. ${ }^{81}$

With their good gloss and nonyellowing characteristics, the main application for polyester acrylic hybrid dispersions has been in inks and coatings.

\section{Alkyd acrylic hybrids}

As already mentioned in "Blends of alkyds and acrylics," the compatibility of alkyds and acrylics is generally poor. ${ }^{37}$ To avoid haze formation and obtain good gloss levels, with fast drying and crosslinking through the autoxidation mechanism, hybrids have been prepared. These can, for convenience, be split into two categories: the one where both acrylic and alkyd are present in one particle; however, still by and large ungrafted and the other where both polymer types are chemically linked together.

A common route to chemically link alkyd and acrylic together is by means of radical polymerization of the acrylate in the presence of the alkyd. ${ }^{82-86}$ The alkyd structure is by nature very hydrophobic and this makes it suitable for use in mini-emulsion polymerization reactions. ${ }^{87}$

An alternative route is to use a polyacrylate in a polycondensation process, for instance by first polymerizing the acrylate in the presence of a fatty acid, which leads to grafting. In a subsequent step, with additionally added building blocks, a polycondensation step is being executed, leading to an alkyd acrylategrafted structure. ${ }^{88}$ By using the sterically hindered methacrylic acid in the acrylic backbone, a composite latex can be prepared which is a core shell structure with the acid functional acrylic on the outside and the more hydrophobic alkyd on the inside of the particle. These hybrids are particularly stable against hydrolysis and have found use in primers for metal, stoving systems, and as primer on wood. ${ }^{89}$

\section{Various other hybrids}

A number of other hybrids have been reported on, all with limited commercial exploitation.

Polydimethylsiloxane (PDMS) is a hydrophobic polymer which combines a low $T_{\mathrm{g}}$ with a low tack. This makes PDMS hybrids ${ }^{90}$ an interesting class of materials for low VOC coatings. To obtain a sufficient level of mechanical performance, the PDMS polymer is covalently bonded to a polymer with a higher $T_{\mathrm{g}}$, for which purpose both polyacrylates and polyurethanes have been reported. ${ }^{91}$

Direct polymerization of PDMS structures is most conveniently done through a mini-emulsion polymerization, optionally via a simultaneous anionic ringopening polymerization and a radical polymerization. ${ }^{92}$ This avoids the need for diffusion of the hydrophobic PDMS precursor structures through the aqueous phase. An application for these hybrids is masonry coatings with excellent outdoor durability, albeit at a price. PDMS has also been used as building block in high-performance alkyds and as building block in aqueous polyurethanes and in urethane acrylic hybrids dispersions, with good water repellency, used in niche applications such as coatings for playing cards and in hair styling polymers. 
Another class of hybrids are epoxy acrylics, ${ }^{93-95}$ which delivers a low VOC system, which is of particular interest for primer applications on metal, architectural coatings, and as coating on concrete. Good adhesion, chemical, and humidity resistances have been reported.

Fluor acrylic hybrids have been utilized for architectural applications and more recently as roof coatings, ${ }^{96}$ and for antigraffiti coatings with strong points being the outdoor durability, low dirt pick up, and stain resistance. Another hybrid type is based on rubber acrylic hybrids, ${ }^{97}$ made by a mini-emulsion route and recommended for adhesives and primers.

\section{Crosslinkable oligomer polymer hybrids}

High acid content oligomers can be used as a seed for an acrylic emulsion polymerization. This is quite useful in applications which are not so demanding in term of resistance level. For high-end applications, hydrophilic material should be avoided if possible and due to the inherent hydrophilicity of these high acid content oligomers, crosslinking becomes desirable to improve the resistance level. The high acid content oligomer not only functions as a stabilizer for subsequent polymerized acrylate monomers but also appears to act as a pigment dispersant. By optimizing the amount of acid monomer in the high acid oligomers used in ink applications, it is possible to maximize these stabilizing and dispersing functions.

The absence of free surfactant eliminates foaming problems and avoids adhesion problems due to surfactant exudation on film formation. By the incorporation of functional groups in both the dispersant (i.e., the oligomer) and the secondly polymerized phase, an inverted core shell morphology can be obtained and on film formation both phases can be crosslinked together. In addition to this, a difference in glass transition temperature between both phases can be applied, which makes these types useful in low VOC coating applications, where fast drying and good block resistance $^{98}$ are required. ${ }^{99}$

\section{Waterborne inorganic organic hybrids}

A recent development in hybrid dispersions is the organic-inorganic hybrid emulsions, like acrylic silica hybrids. These nanocomposite materials can be made through blending, the sol-gel process, ${ }^{100}$ or nanosized silica can be incorporated during a (mini) ${ }^{101}$ emulsion polymerization process ${ }^{102,103}$ in which silane coupling agents are preferably used to achieve miscibility of the acrylic and the silica. ${ }^{104}$ Good solvent resistances have been reported for these hybrids.

Other inorganic-organic hybrids include clay acrylic dispersions ${ }^{105}$ for instance to obtain oxygen and moisture ${ }^{106}$ barrier properties and for increased stiffness and rheology modification. ${ }^{105}$
The increased storage and tensile moduli are attributed to the local restrictions on the matrix mobility in the vicinity of the rigid nanosized clay particles. ${ }^{107}$

In an alternative process, latex-templated particles are prepared whereby a silica shell is built on the outside of the acrylic particle by sol-gel technology. ${ }^{108,109}$ The resins comprising these core shell polymer-metaloxide nanoparticles find application in, e.g., antireflective coatings.

\section{Heterogeneity control within a single polymer chain}

\section{Controlled radical polymerization}

A very sophisticated control over the design of polymers has become possible by the emerging technology of controlled radical polymerization (CRP). ${ }^{110}$ In CRP, all polymer chains grow at approximately the same rate throughout the complete reaction time which allows designing any type of polymer with controlled composition simply by the order of addition of the monomers to the polymerization reactor.

For most CRP techniques, a very narrow $\mathrm{Mw}$ distribution is easily achieved. ${ }^{111}$ This opens opportunities for high solids solventborne paints due to the absence of a high $\mathrm{Mw}$ fraction, which dominates the viscosity of these paints. Also in waterborne paints with a good DOI, it is important to have a good flow out in advanced stages of the drying process and also here high $\mathrm{Mw}$ should be avoided for reasons of viscosity build-up and low $\mathrm{Mw}$ should be avoided to obtain good final properties or a sufficient rate of drying.

There are several routes to make controlled polymeric structures. One route makes use of catalytic chain transfer polymerization, which results in terminally unsaturated oligomers that can be grafted to end up as side chain. ${ }^{112-114}$ The cobalt-based chain transfer agent is already effective in the low ppm range, provided methacrylate monomers are predominantly used, and by grafting with acrylic monomers, comb polymer structures can readily be produced.

Another method makes use of living free radical methods, like nitroxide-mediated polymerization (NMP), atom transfer radical polymerization (ATRP), and reversible addition fragmentation chain transfer polymerization (RAFT).

$\mathrm{NMP}^{115}$ is less preferred in water, due to the high temperatures needed and ATRP ${ }^{116}$ suffers from the need to remove copper from the polymer and the problem that acid functional monomers cannot be used in the process.

RAFT polymerization, ${ }^{117}$ however, appears a rather universal tool for making water-dispersable acrylic block copolymers. It is well known that RAFT agents, which are thiocarbonylthio compounds of general structure $\mathrm{Z}-\mathrm{C}(=\mathrm{S}) \mathrm{SR}$, generally suffer from serious 

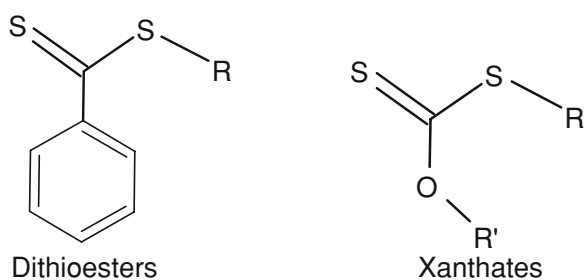

Fig. 6: Structure of RAFT agents of the dithioester and the xanthate type

drawbacks like strong color and malodor. ${ }^{118,119}$ Careful selection of the RAFT agent can therefore be very important, especially when making polymers for coating applications. For example, RAFT agents of the dithioester type $(Z=$ phenyl) are known to exhibit a very strong color, whereas those of the xanthate type ( $\mathrm{Z}=$ alkoxy) are mostly mildly colored (Fig. 6).

Furthermore, apart from unwanted color and odor issues, the presence of the residual thiocarbonylthio group at the polymer chain end can be undesirable from a reactivity and/or potential degradation point of view. Numerous methods for RAFT end-group removal have already been reported in the literature. ${ }^{120,121}$

Several polymer structures produced by CRP have been reported, including $\mathrm{AB}$ block copolymers, ${ }^{122}$ multiblock structures, star ${ }^{123}$ polymers, and comb polymers. The most widely researched types are simple block copolymers, where each block performs a different role. One block can, for instance, be designed to adhere to a substrate and the other block can have build-in crosslink functionality to obtain a combination of both adhesion and resistance. An example of this effect is given in section "Adhesion to untreated polypropylene."

The research on CRP has been directed to many application areas, with the first commercialization being in dispersants ${ }^{124}$ and decorative paints. Amphiphilic block copolymers are of special interest to waterborne paints. They may function as surfactant during polymerization, thus avoiding problems like water sensitivity and adhesion failure due to surfactant migration to surfaces. See also section "Amphiphilic polymers."

\section{Polyurethanes}

Aqueous polyurethanes ${ }^{125}$ are an interesting class of block copolymers. The hard-soft segmentation of these block copolymers is responsible for the good mechanical properties of this polymer class. The hard segment is built-up from diisocyanates, short diols like, for instance, dimethylol cyclohexane, butane diol and dimethylol propionic acid, and the diamine chain extenders like isophorone diamine, hydrazine, and ethylene diamine. For the soft segments, polyols are commonly used, like diols from polypropylene glycol, poly tetrahydrofuran, polycarbonate diols, and polyester diols, generally with Mn from 1000 to 3000. The glass transition temperature of the hard segment varies between 180 and $220^{\circ} \mathrm{C}$ and the soft segment is typically between -50 and $-10^{\circ} \mathrm{C}$. The hydrogen bonding of the polyurethanes strongly contributes to the strength of the polyurethanes.

As earlier described, the Mw of the polyurethanes is built up by a chain extension reaction, which introduces urea groups in the urethane backbone. It would therefore be more correct to describe these dispersions as polyurethane polyurea polymers.

It is well known that urea functionalities in polymer systems are capable of forming dimeric self-complementary multiple hydrogen bonding between the carbonyl oxygen and the two neighboring $\mathrm{N}-\mathrm{H}$ hydrogens. It has been shown that these hydrogen bonding interactions improve the properties of both polyureas and poly(urethane urea)s. ${ }^{126-128}$

Due to this combination of covalent bonding of hard and soft segments and the noncovalent bonding by the multiple hydrogen bridges, a wide range of unique physical performance can be attained and this has led to application in areas like flooring, scratch-resistant coatings, adhesives, glass fiber sizings, and polymers for leather.

\section{Amphiphilic polymers}

Polymers with an amphiphilic character give a heterogeneous behavior due to their molecular architecture and can be seen as a typical example of self-structuring materials. Such polymers can be made very effectively by controlled polymerization techniques. ${ }^{129}$ Control over the internal polymer structure leads to hydrophobic and hydrophilic segments which micro-phase separate and restructure themselves as a function of parameters like solids content, $\mathrm{pH}$, variation in cosolvent level, and salt level.

Fatty acid functional self-dispersing polymers ${ }^{130}$ are distinctly different examples of these amphiphilic structures, and from a rheology perspective, these materials can behave quite similar to solvent-based alkyds with a high oil length.

At an early stage in the drying process, the polymer molecules display a percolation of aggregated hydrophobic fatty acid chains, while hydrophilic groups orient themselves to the aqueous medium. The rheology ${ }^{131}$ and conductivity measurements given in Figs. 7 and 8 are in agreement with the formation of a bicontinuous phase of polymer and water.

Before going into any depth to the application of these amphiphilic fatty acid functional polymers, it is useful to have a closer look at certain flow aspects of waterborne paints and how this differs from solvent alkyds with high oil length.

For a good brushability and open time, brush marks should flow away and this requires a low viscosity at the stage the paint should still be "open" as can be 
illustrated by the following formula for undulation of a liquid $^{132}$ :

$\frac{d a}{d t}=\frac{16 \pi^{4} h^{3} \gamma a}{3 \lambda^{4} \eta}$

where $a$ denotes amplitude; $t$ time; $h$ average film thickness; $\lambda$ distance between striations; $\gamma$ surface tension; and $\eta$ viscosity.

Where surface tension may vary by a factor of 4 , viscosity of a drying paint film will cover several decades in magnitude, hence making viscosity development during the first 20-30 min of drying the most relevant factor for flow out of brush marks.

As shown in section "Heterogeneity in terms of polymer viscosity," a combination of polymers with a low and a high viscosity can give the required slow rate of viscosity build-up to give good brushability to the paint.

There is, however, still another striking difference in the flow behavior on drying between solvent-based alkyds with a high oil length and aqueous dispersions, even when combined with a low-viscous polymer. This only becomes apparent after more than $40 \mathrm{~min}$ of drying, which is well after the time required for the brush marks to flow away.

The current waterborne paints show a faster rate of viscosity increase in the time frame of 35-80 min after application of the paint to a substrate (see also thin film

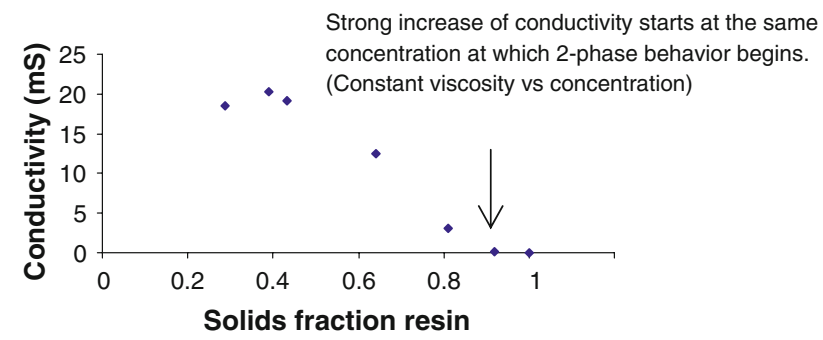

Fig. 7: Conductivity during drying of a fatty acid functional self-dispersing polymer analyser (TFA) Fig. 5). This relatively faster viscosity increase leads to a notable telegraphing of the substrate roughness to the surface of the paint and this phenomenon is believed to be responsible for the strong decrease in the mirror-like reflection of the waterborne paints.

To illustrate the effect of the addition of polymer with a high viscosity on the telegraphing of the substrate roughness to the surface of a coating, a fatty acid functional urethane dispersion with high viscosity @ $100 \%$ polymer was added at different levels to an amphiphilic fatty acid functional material with low viscosity (@100\% polymer), see Fig. 9.

By increasing the ratio of high-viscosity polymer to low-viscous polymer ("oligomer" in this case), a strong decrease in gloss level due to an increase in telegraphing becomes apparent.

The reduction in telegraphing is depicted by showing the gloss levels on both rough PVC $(\mathrm{Rz}=25 \pm$ $2 \mu \mathrm{m})$ and smooth PVC $(\mathrm{Rz}=1 \pm 0.1 \mu \mathrm{m})$. The gloss on smooth PVC does not suffer from telegraphing effects and is taken as $100 \%$ at all blend ratios. The reduction in gloss for the rough PVC compared to the smooth reference is presented in Fig. 9.

As can be seen, the gloss value at $20^{\circ}$ angle is reduced by $50 \%$ when $35 \mathrm{wt} \%$ of high-viscous polymer is present.

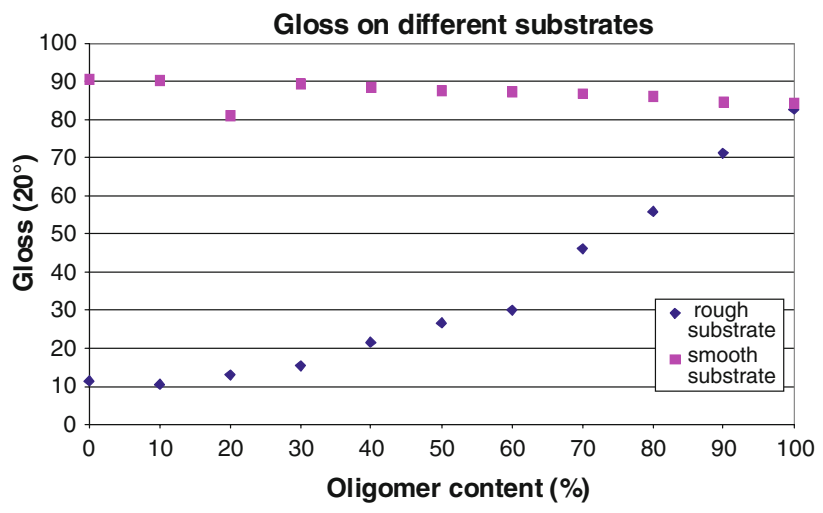

Fig. 9: Influence of blend ratio high-viscous/low-viscous polymer on gloss

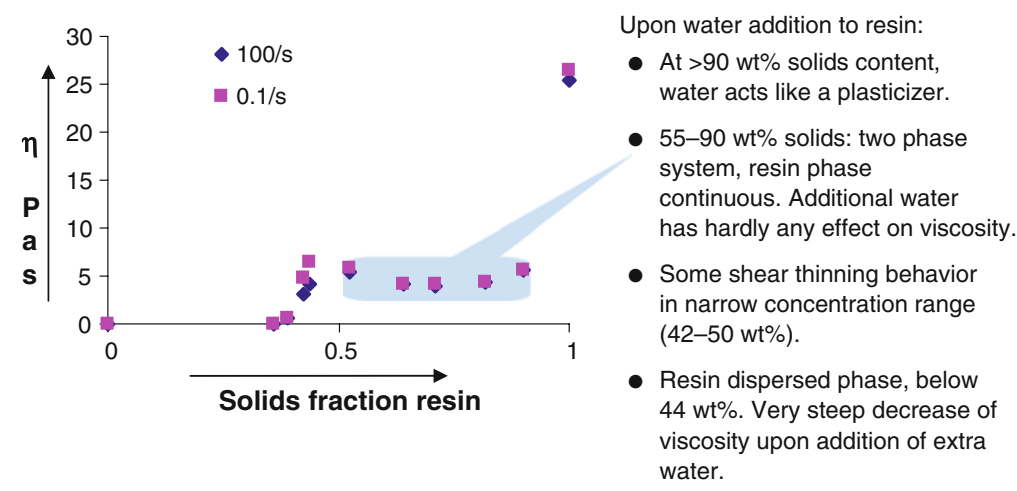

Fig. 8: Viscosity at different shear rates as function of solids fraction 


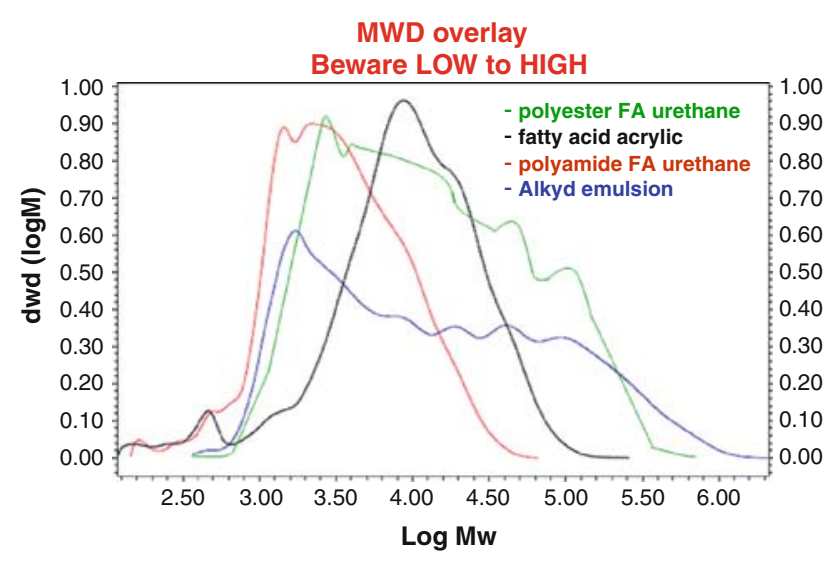

Fig. 10: Molecular weight distribution for different types of fatty acid functional polymers

This all leads to the conclusion that for a combination of good brushability, open time, and DOI of the paint, it is necessary to use a polymer which maintains a low viscosity, not only in the first $30 \mathrm{~min}$ after application but also in the next 30-50 min.

Conventional solvent-based alkyds with a high oil length have the advantage of the presence of relatively high levels of solvents which will reduce the viscosity of this fairly viscous polymeric material. To avoid high levels of solvent and still have a fast Mw build up, a faster crosslinking reaction would be required than known for traditional alkyd paints.

As explained in section "Heterogeneity in terms of polymer viscosity," the crosslink mechanism for the oligomer should preferably result in a one-pack system, contribute to the required low viscosity, and be economical, and for these reasons, autoxidation of fatty acid functionality seems to be the most appropriate crosslink mechanism. Real new advances in crosslink chemistry which fit the requirement of contributing to a low viscosity and price are currently not available and therefore the $\mathrm{Mw}$ distribution has been investigated as parameter to influence the rate of building up the Mw.

In Fig. 10, the Mw distributions of different low Mw fatty acid functional materials are given. The alkyd emulsion gives the broadest $\mathrm{Mw}$ distribution. The high Mw part will result in a high viscosity which is unwanted from a telegraphing point of view, especially when low levels of solvent will be used or no solvent at all. The low $\mathrm{Mw}$ part deteriorates the rate of drying and leads to an increased dust and tack-free time. Given the need to accelerate in drying rate after the critical period for telegraphing is gone, also this low Mw part needs to be eliminated.

The "polyamide fatty acid functional urethane" and the "polyester fatty acid functional urethane" presented in Fig. 10 both have the advantage of elimination of the high Mw peak, which makes them both suitable for both "open time" and good DOI performance.
Table 1: Molecular weight distribution for different types of fatty acid functional polymers

\begin{tabular}{lrrr} 
& Mn & Mw & Pd \\
\hline Polyester FA urethane & 2862 & 17,498 & 6.1 \\
Fatty acid acrylic & 3560 & 14,902 & 4.2 \\
Polyamide FA urethane & 2043 & 5,290 & 2.6 \\
Alkyd emulsion & 4145 & 61,000 & 14.7 \\
\hline
\end{tabular}

Due to the presence of some low Mw material, both will show a longer drying time compared to the alkyd emulsion. Finally, the fatty acid functional acrylic shows the narrowest $\mathrm{Mw}$ distribution with both low and high $\mathrm{Mw}$ materials being absent.

This gives the promise of a potential good DOI and also the potential for a fast development of properties after this initial drying stage.

More details on the Mw of the different fatty acid functional polymers can be found in Table 1 .

For additional experimental details and results on telegraphing see "Experimental" section.

\section{Experimental}

\section{Influence of nanostructure on film formation and mechanical properties}

Sequential polymerization of two polymer phases with different $T_{\mathrm{g}}$ is a useful tool to reduce coalescent demand while at the same time improving the resistance of the coating to blocking. In Table 2, different polymerization routes and $T_{\mathrm{g}} \mathrm{s}$ are compared for their influence on VOC, hardness, MFT, and block resistance. ${ }^{98}$

The blend shows a higher elongation and lower hardness compared to both sequential polymerization routes. This can be explained by the lower amount of interfacial material of the blend when compared to both sequential lattices. The low/high $T_{\mathrm{g}}$ route for the sequential polymer gives the highest tensile strength, which again is most likely due to a better mixing of both phases compared to the high/low $T_{\mathrm{g}}$ sequence. Monomer and oligo radicals from the second phase will more easily penetrate in a low $T_{\mathrm{g}}$ first phase than in a high $T_{\mathrm{g}}$ phase. This technology is useful for industrial wood applications like window frames and for decorative paints, where low VOC levels and good block resistance are required.

\section{Influence of sequential polymerization on mechanical properties for highly elastic films}

A sequentially polymerized acrylate was prepared with $80 \mathrm{wt} \%$ of a first phase with calculated $T_{\mathrm{g}}$ of $-11^{\circ} \mathrm{C}$ and $20 \mathrm{wt} \%$ of a second phase with a calculated $T_{\mathrm{g}}$ of $80^{\circ} \mathrm{C}$. 
Table 2: Influence of $T_{\mathrm{g}}$ and sequence of polymerization on mechanical properties of multiphase acrylics

\begin{tabular}{|c|c|c|c|c|c|c|}
\hline Polymer & 1 & 2 & 3 & 4 & 5 & 6 \\
\hline Phase $T_{\mathrm{g}}$ (theoretical) & $4^{\circ} \mathrm{C} / 80^{\circ} \mathrm{C}$ & $80^{\circ} \mathrm{C} / 4^{\circ} \mathrm{C}$ & Average composition & $80^{\circ} \mathrm{C}$ & $4^{\circ} \mathrm{C}$ & Blend $4^{\circ} \mathrm{C} / 80^{\circ} \mathrm{C}$ \\
\hline Phase ratio & $70 / 30$ & $30 / 70$ & n.a. & n.a. & n.a. & $70 / 30$ \\
\hline$T_{\mathrm{g}}$ measured by DSC & $5 / 93$ & $5 / 91$ & 24 & 90 & -1 & $3 / 86$ \\
\hline $\mathrm{MFT}\left({ }^{\circ} \mathrm{C}\right)$ & 1 & 1 & 22 & 84 & $<0$ & $<0$ \\
\hline Butyl glycol (\%) ${ }^{a}$ & 0 & 0 & 12 & 28 & 4 & 8 \\
\hline König hardness & 35 & 34 & & n.a & 7 & 15 \\
\hline Block resistance @ $50^{\circ} \mathrm{C}$ & + & 0 & - & ++ & - & - \\
\hline Tensile strength $\left(\mathrm{N} / \mathrm{mm}^{2}\right)$ & 3.9 & 2.9 & 1.2 & n.a. & 1 & 3 \\
\hline Elongation at break (\%) & 358 & 361 & 337 & n.a. & 664 & 421 \\
\hline
\end{tabular}

a Butyl glycol (\%) : percentage needed for good film formation @ $4^{\circ} \mathrm{C}$ on absorbing substrate

Compositions of the polymers: Low $T_{\mathrm{g}}\left(4^{\circ} \mathrm{C}\right)-\mathrm{BA} / \mathrm{BMA} / \mathrm{MMA} / \mathrm{AA}=28.6 / 61.1 / 5.3 / 5.0$; $\mathrm{High} T_{\mathrm{g}}\left(80^{\circ} \mathrm{C}\right)-\mathrm{BMA} / \mathrm{MMA} / \mathrm{AA}=24.1 /$ 70.9/5.0\%; Average $T_{\mathrm{g}}\left(20^{\circ} \mathrm{C}\right)$-BA/BMA/MMA/AA $=20 / 50 / 25 / 5$

BA, butyl acrylate; MMA, methyl methacrylate; BMA, butyl methacrylate; AA, acrylic acid

Table 3: Composition of soft sequential polymer

\begin{tabular}{lccc} 
& Phase 1 & Phase 2 & Overall \\
\hline BA & 44.4 & - & 35.5 \\
BMA & 53.6 & 26.1 & 48.1 \\
MMA & - & 71.9 & 14.4 \\
MAA & 2 & 2 & 2 \\
$T_{\mathrm{g}}\left({ }^{\circ} \mathrm{C}\right)$ & -11 & 80 & 3 \\
Ratio & 80 & 20 & - \\
\hline
\end{tabular}

Table 4: Influence of polymerization method on elongation and toughness

\begin{tabular}{lcc}
$\begin{array}{l}\text { Polymerization } \\
\text { method }\end{array}$ & $\begin{array}{c}\text { Elongation } \\
(\%)\end{array}$ & $\begin{array}{c}\text { Toughness } \\
(\mathrm{kPa})\end{array}$ \\
\hline Soft/hard & 900 & 13,500 \\
Hard/soft & 500 & 5,250 \\
Average & 550 & 4,000 \\
Physical blend of soft & $>900$ & 3,500 \\
$\quad$ and hard & & \\
\hline
\end{tabular}

For compositional details see Table 3.

The elongation and toughness were measured and compared with the sequential polymer where the two phases were prepared in reverse order, the physical blend of both phases and the average composition. For results see Table 4.

The remarkably high toughness of the soft-hard polymerized material can be explained by the likelihood of the formation of more interfacial material when compared to the hard-soft polymerization sequence. It will come as no surprise that lower toughness values are obtained with both the average composition and the physical blend. This technology is of interest in applications where zero VOC is of importance.

\section{Comparison of mechanical properties of urethane acrylic blends and hybrids}

Mechanical properties are of importance in most coating applications.

For outdoor durable coatings on wood, it is important for the coating to be able to follow the movement of wood caused by temperature or humidity variations.

For floor coatings, the abrasion and scratch resistance can be directly related to modulus and elasticity.

In Fig. 11, AFM pictures of a hybrid and the equivalent blend of a polyurethane with an acrylic of $T_{\mathrm{g}} 78^{\circ} \mathrm{C}$ is shown. The large number of acrylic-acrylic contact points is clearly visible for the blend and these weak interfaces will severely degrade the mechanical performance of the blends compared to the hybrid.

Figure 12 shows the difference in modulus and elasticity of a waterborne polyurethane, an acrylic dispersion of high $T_{\mathrm{g}}$, the blend of both (see also Fig. 11 for the AFM) and the urethane acrylic hybrid (see also Fig. 11 for the AFM).

The blend of urethane and acrylic will have a low amount of interfacial material as discussed in section "Urethane acrylic hybrids" and this is believed to be the main reason why the mechanical properties are inferior compared to the urethane acrylic hybrid.

These urethane acrylic hybrids are suitable for parquet flooring, industrial wood, and decorative paints.

\section{Adhesion to untreated polypropylene}

Polypropylene (PP) is a widely used substrate, which needs a pretreatment or a special primer, such as chlorinated polyolefins to obtain good adhesion. A long-lasting desire is to obtain adhesion to untreated $\mathrm{PP}$, from an aqueous paint, which avoids the use of chlorinated polymers or other expensive pretreatment. 

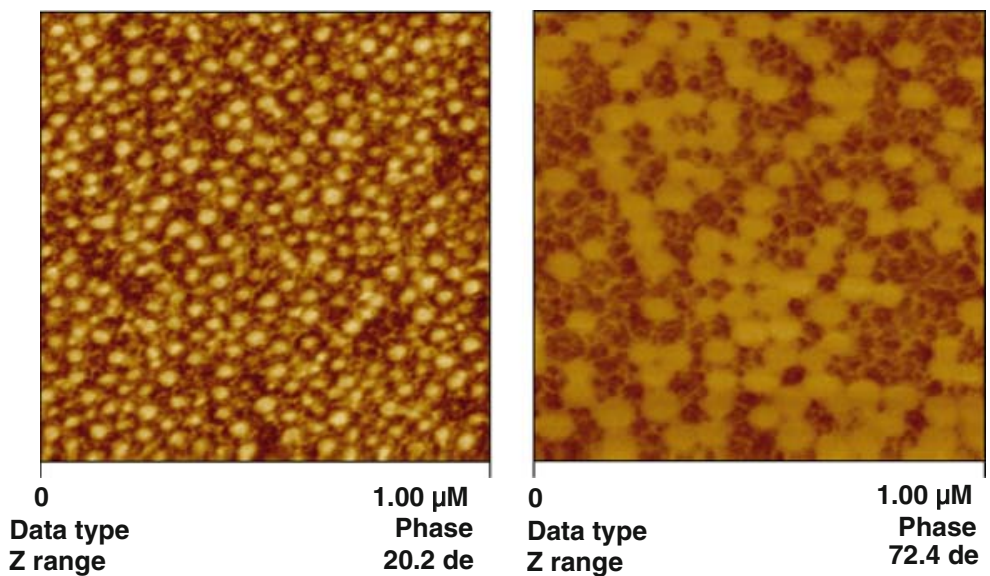

Fig. 11: AFM pictures of urethane acrylic hybrid (left) and the corresponding blend (right)

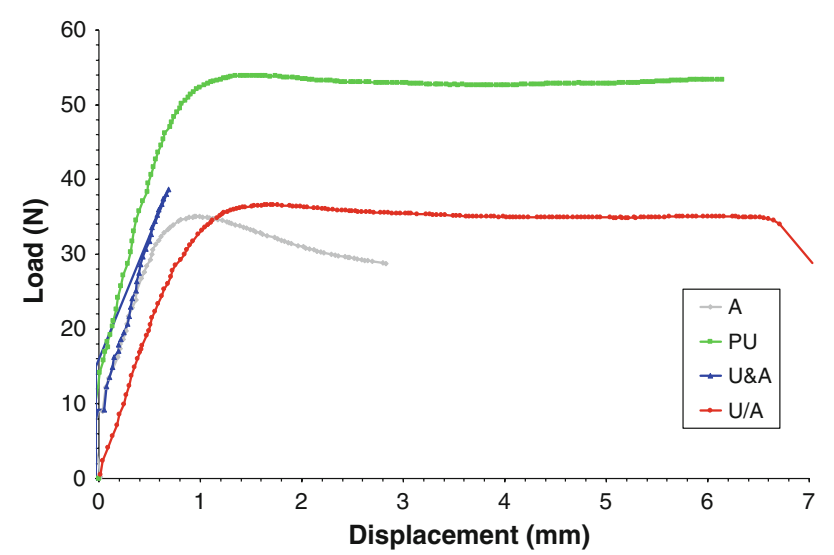

Fig. 12: Comparison of tensile properties of urethane acrylic hybrids and references

Some polymers have been reported to give a certain degree of adhesion to untreated PP, but all have disadvantages. One example is poly isobornyl acrylate (iBOA), which is an extremely brittle material that loses its adhesion when mechanical forces are applied to it.

The contradiction of combining a good adhering iBOA chain and a good flexibility within the same material can be resolved by using block copolymers.
For the adhesion to untreated PP, block copolymers were designed containing both the iBOA block and more flexible blocks, such as poly butyl acrylate, which brings sufficient resilience to the coating. The block copolymer with an iBOA and a butyl acrylate block, made by using the RAFT technology, is shown in Table 5.

The block copolymer, based on a first stage in which subsequently a block of acrylic acid and a block of isobornyl acrylate are polymerized, followed by a second-stage emulsion polymerization of butyl methacrylate and butyl acrylate, gives excellent adhesion. In contrast to this, both the average polymer and the sequential polymer where isobornyl acrylate is used in a second phase (inverse core shell morphology) lack adhesion to the untreated polypropylene.

This shows that not only the intrapolymer structure is relevant for adhesion but also that the kinetics involved in the migration of adhering blocks to the surface of the polypropylene plays an important role. Where all acid is used in a block which also contains the iBOA, the hydrophobic adhering blocks are pulled to the surface of the particle and hence it can easily diffuse into the PP substrate (Fig. 13). In the case of the sequential polymer, the adhering blocks are buried inside the particle and due to the slow diffusion kinetics, the material lacks adhesion.

Table 5: Influence block copolymer structure on adhesion

\begin{tabular}{|c|c|c|c|c|c|c|}
\hline \multirow[t]{2}{*}{$\begin{array}{l}\text { WB acrylic } \\
\text { dispersion }\end{array}$} & \multirow[t]{2}{*}{$\begin{array}{l}\text { Phase } 1 \\
\left(T_{\mathrm{g}}\right)\end{array}$} & \multirow[t]{2}{*}{$\begin{array}{l}\text { Phase } 2 \\
\left(T_{\mathrm{g}}\right)\end{array}$} & \multicolumn{3}{|c|}{$\begin{array}{l}\text { Untreated OPP foil } \\
\text { (tape test: \% removed) }\end{array}$} & \multirow[t]{2}{*}{$\begin{array}{l}\text { Untreated PP plates (GT) } \\
(0=\text { excellent, } 5=\text { poor })\end{array}$} \\
\hline & & & Scotch 810 & Scotch 610 & Scapa red & \\
\hline Block copolymer & $\mathrm{AA}_{x}-\mathrm{iBOA}_{y}\left(95^{\circ} \mathrm{C}\right)$ & $\mathrm{BMA} / \mathrm{BA}\left(0^{\circ} \mathrm{C}\right)$ & 0 & 0 & 20 & 0 \\
\hline Single phase & $\begin{array}{l}\mathrm{BMA} / \mathrm{BA} / \mathrm{iBOA} / \mathrm{AA} \\
\left(15^{\circ} \mathrm{C}\right)\end{array}$ & - & 100 & 100 & 100 & 5 \\
\hline Sequential & $\mathrm{BMA} / \mathrm{BA} / \mathrm{AA}\left(0^{\circ} \mathrm{C}\right)$ & iBOA/AA $\left(95^{\circ} \mathrm{C}\right)$ & 100 & 100 & 100 & 5 \\
\hline
\end{tabular}




\section{Telegraphing studies}

Telegraphing has been studied by using a white light interferometer. The white light interferometer allows a time-resolved 3D visualization of the paint surface. ${ }^{133}$

In Fig. 14, the gloss difference between the solvent alkyd and the waterborne acrylic paint emerges long after the brush marks had disappeared, which confirms that telegraphing and brush mark flow out are two consecutive events.

The differences in flow behavior during drying for a typical solvent-based alkyd and an aqueous acrylic dispersion are depicted in Figs. 15-18.

From Figs. 17 and 18 it can be concluded that telegraphing of the roughness of the substrate to the surface of the coating starts at a much earlier moment

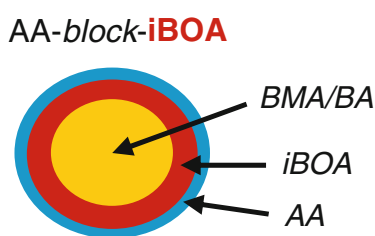

Block polymer

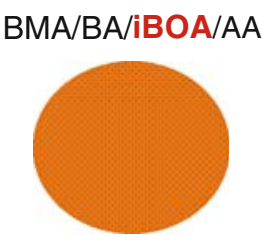

Single phase

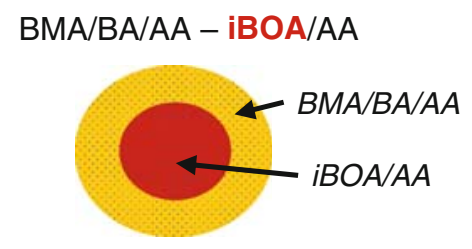

Sequential

Fig. 13: Influence of polymer architecture on particle morphology and adhesion
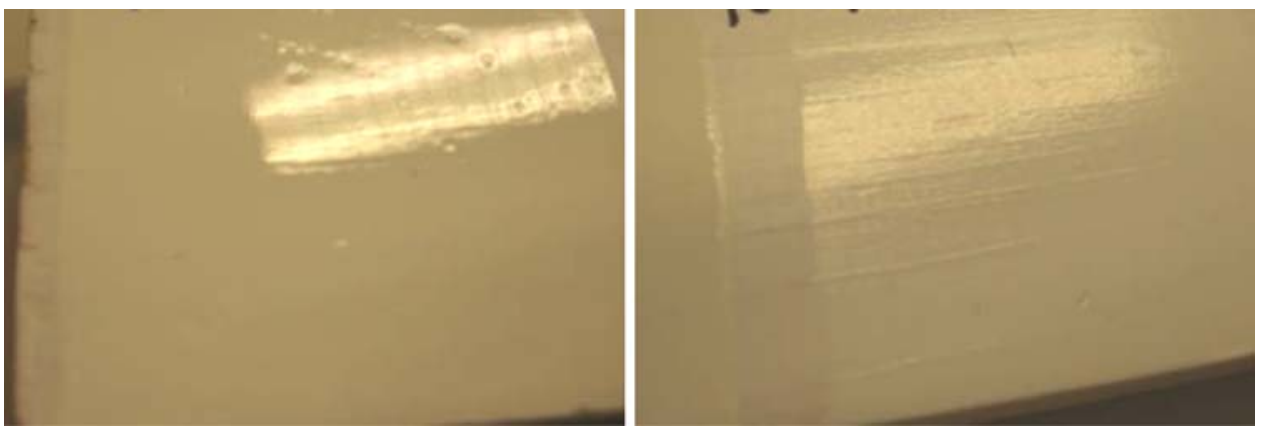

Fig. 14: Gloss differences due to telegraphing: solvent-based paint (left) and a waterborne paint (right)
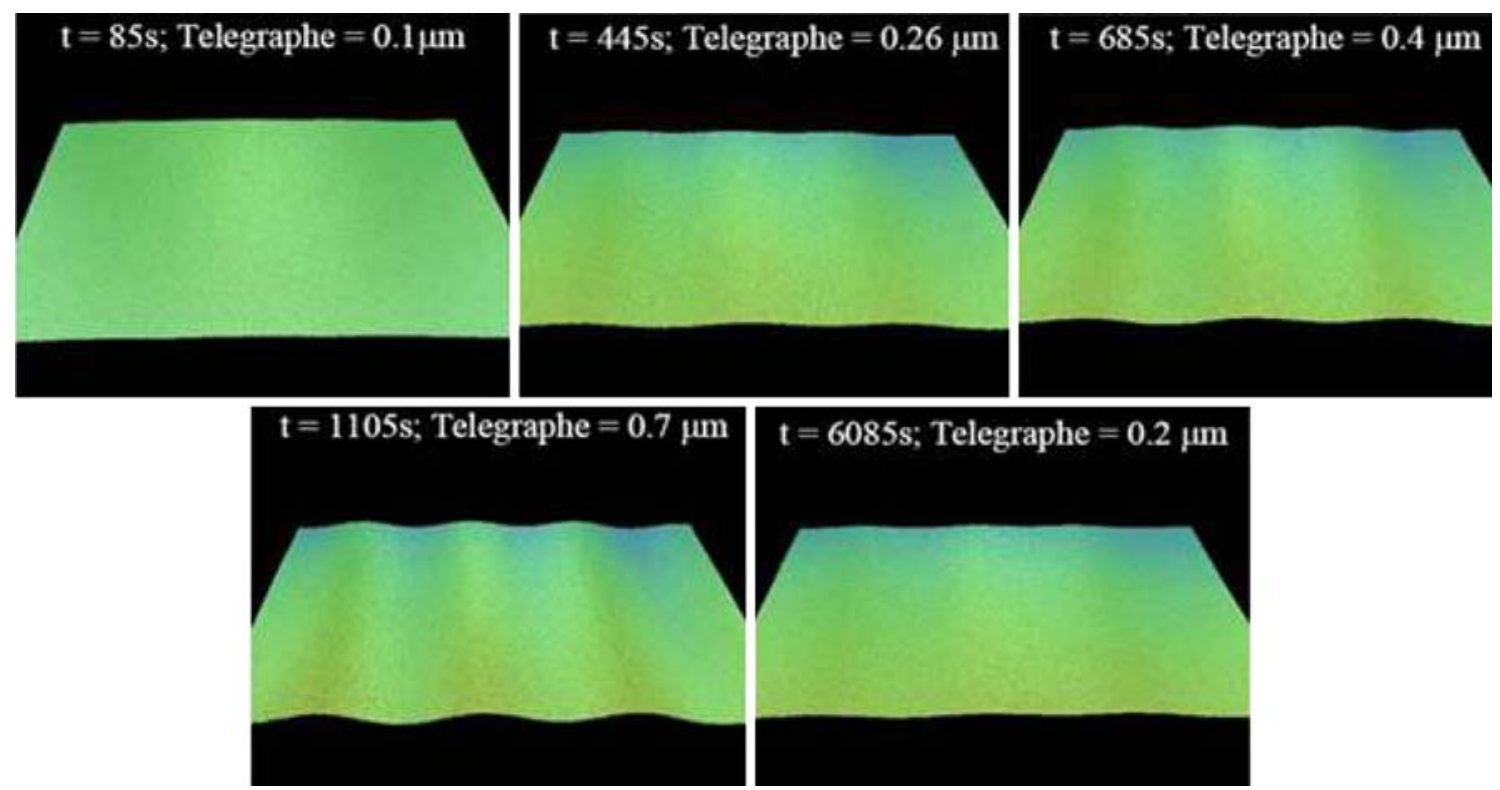

Fig. 15: Telegraphing of the substrate roughness of a solvent-based paint during the drying process $\left(\sim 23^{\circ} \mathrm{C} ; \sim 50 \mathrm{RH} \%\right.$; $\sim 50 \mu \mathrm{m}$ wet paint layer applied) 

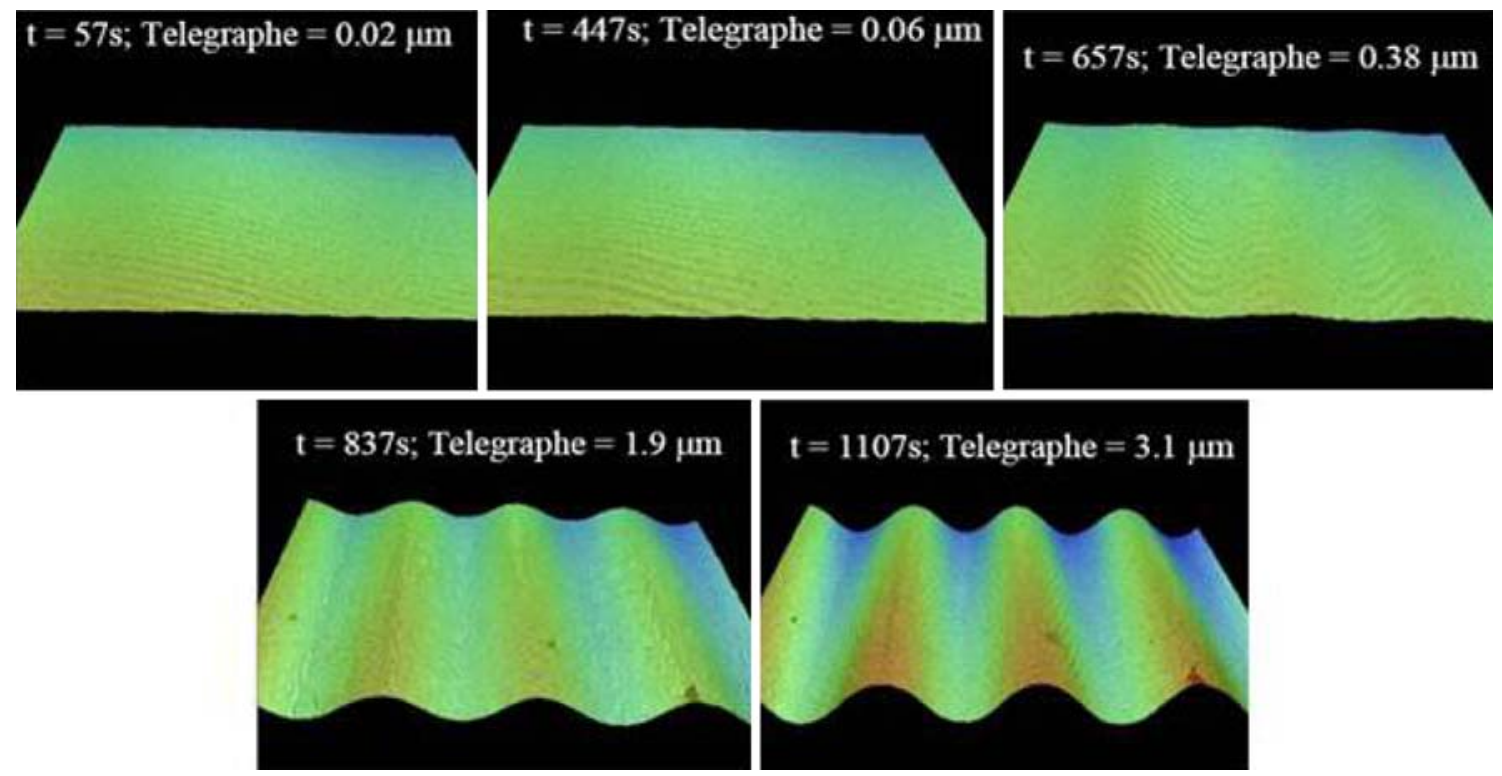

Fig. 16: Telegraphing of substrate roughness of a conventional waterborne paint during the drying process $\left(\sim 23^{\circ} \mathrm{C}\right.$; $\sim 50 \mathrm{RH} \%$; $\sim 75 \mu \mathrm{m}$ wet paint layer applied)

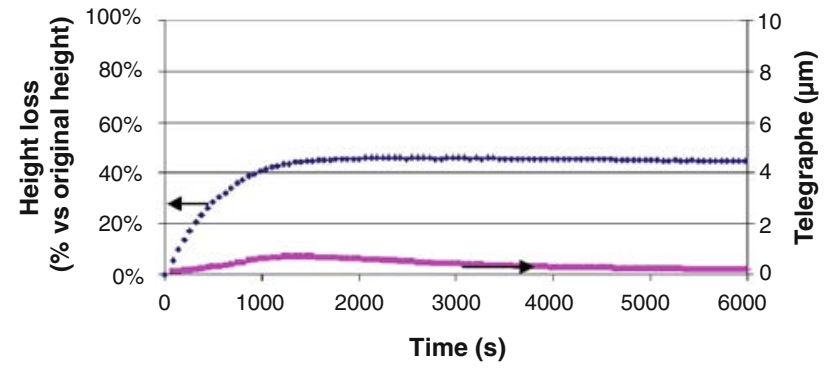

Fig. 17: The development of the solids content of a solvent-based paint in time

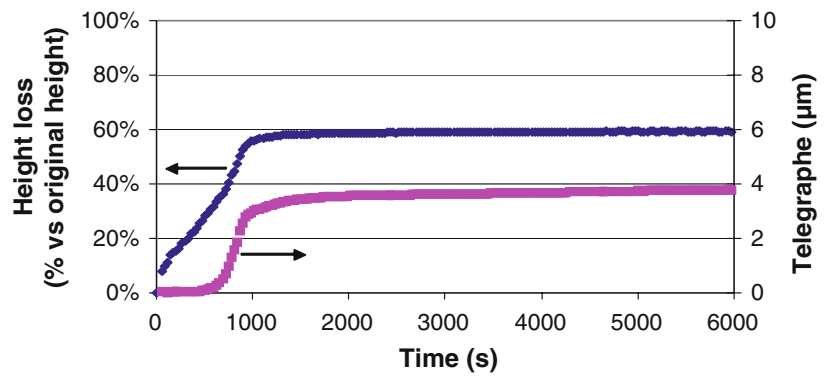

Fig. 18: The development of the solids content of a waterborne paint in time
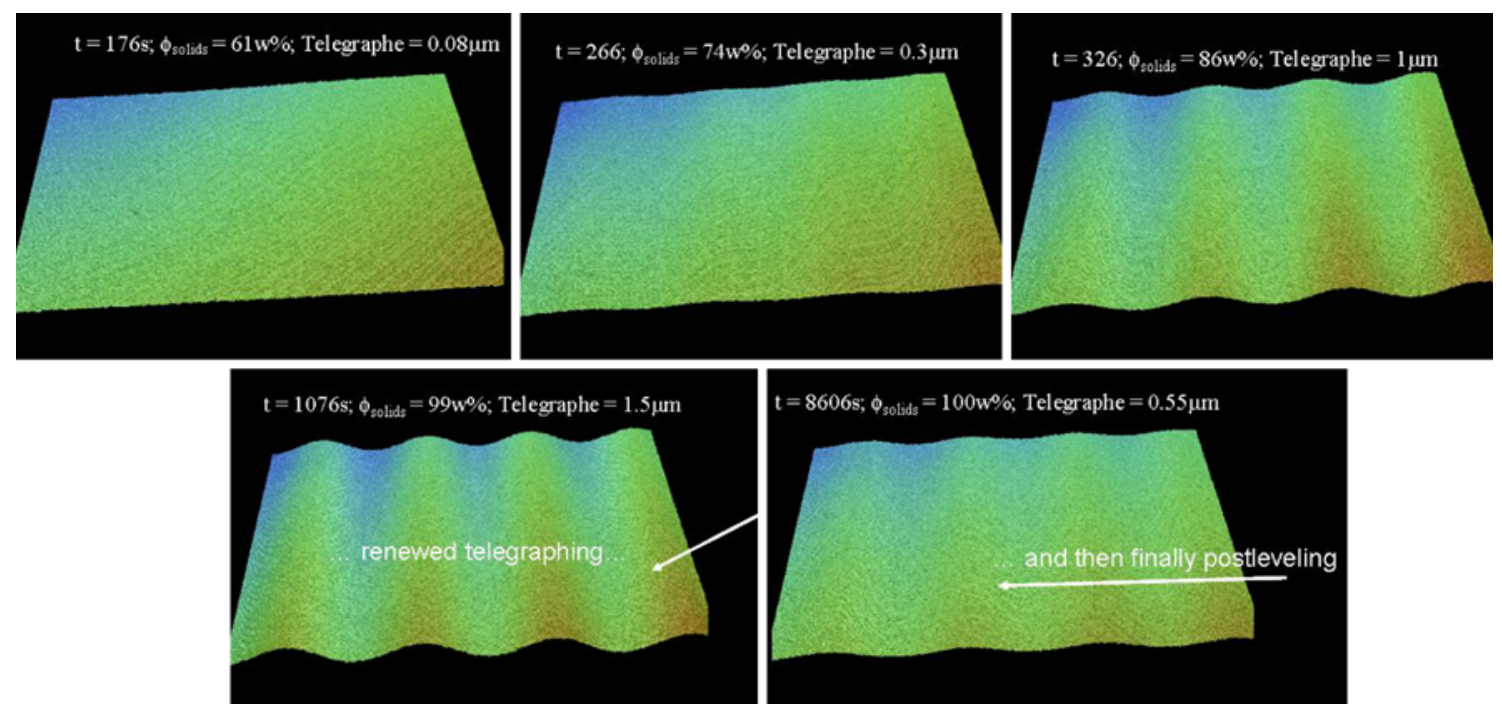

Fig. 19: Telegraphing of the substrate roughness of a "low viscosity at $100 \%$ solids" waterborne paint during the drying process $\left(\sim 23^{\circ} \mathrm{C}\right.$; $\sim 50 \mathrm{RH} \%$; $\sim 75 \mu \mathrm{m}$ wet paint layer applied) 
in time for the solvent-based paint when compared to the waterborne paint. The postleveling between 99 and $100 \%$ solids, however, is much better for the solventbased paint, which explains the much better gloss of certain solvent-based alkyd paints, in comparison to, for instance, waterborne acrylic paints.

A major step to bridge this gap in postleveling has been made (see Fig. 19) by tailoring the $T_{\mathrm{g}}$ and Mw of the waterborne resins in such a way that the viscosity becomes sufficiently low in the solids range of 99$100 \%$ to allow the postleveling to take place.

Other factors do play a role as well and the avoidance of a yield stress in particular is a key factor to bring waterborne paints to a similar gloss level as can be achieved with high oil solvent-based alkyd paints.

\section{Conclusion}

By increasing the control over polymer and particle architecture and by controlling the film formation process and in particular the final film morphology, waterborne resin technology has become the technology of choice for an increasing variety of applications. Polymer heterogeneity control was and will be a key tool to resolve challenges in the waterborne coating industry making waterborne technology even more widely applicable and ultimately replacing solventborne coating technology in virtually all coating segments. This will lead to much improved safety for the workers in the industry and at home, a lower health impact, and a much improved environmental profile.

Acknowledgments The author wishes to thank John Padget, Ronald Tennebroek, Jeffrey Stubbs, Tijs Nabuurs, Dorina van Haeringen, Yvonne Smak, Mike Schellekens, Fred Buckmann of DSM NeoResins ${ }^{+}$, and Leon Bremer, Remco Tuinier and Filip Oosterlinck of DSM Research, for their contributions and discussions.

Open Access This article is distributed under the terms of the Creative Commons Attribution Noncommercial License which permits any noncommercial use, distribution, and reproduction in any medium, provided the original author(s) and source are credited.

\section{References}

1. Padget, JC, "Polymers for Water-Based Coatings-A Systematic Overview." J. Coat. Technol., 66 (839) 89-105 (1994)

2. Hoover, WG, Ree, FH, "Melting Transition and Communal Entropy for Hard Spheres.” J. Chem. Phys., 49 3609-3617 (1968)
3. Pusey, PN, Van Megen, W, "Phase Behaviour of Concentrated Suspensions of Nearly Hard Colloidal Spheres." Nature, 320 (6060) 340-342 (1986)

4. Bolhuis, PG, Kofke, DA, "Monte Carlo Study of Freezing of Polydisperse Hard Spheres." Phys. Rev. E, 54 (1) 634643 (1996)

5. Pedraza, EP, Soucek, MD, "Bimodal Particle Distribution for Emulsions: The Effect of Interstitial Functional Particles." Eur. Polym. J., 43 (4) 1530-1540 (2007)

6. Kim, IT, Luckham, PF, "Some Rheological Properties of Bimodal Sized Particulates." Powder Technol., 77 31-37 (1993)

7. Peters, ACIA, Overbeek, GC, Buckmann, AJP, Padget, JC, Annable, T, "Bimodal Dispersions in Coating Applications." Prog. Org. Coat., 29 (1-4) 183-194 (1996)

8. Guyot, A, Chu, F, Schneider, M, Graillat, C, McKenna, TF, "High Solid Content Latexes." Prog. Polym. Sci., 27 (8) 1573-1615 (2002)

9. Schneider, M, Graillat, C, Guyot, A, McKenna, TF, "High Solids Content Emulsions. II. Preparation of Seed Lattices." J. Appl. Polym. Sci., 84 (10) 1897-1915 (2002)

10. Muller, H, "Preparation of Multimodal Polymer Dispersions Using Polymeric Stabilizer, and Use There of." US Patent 7,358,297, 2008

11. Rodriguez, BE, Kaler, EW, Wolfe, MS, "Binary Mixtures of Monodisperse Latex Dispersions. 2. Viscosity." Langmuir, 8 (10) 2382-2389 (1992)

12. Loehr, G, Reinecke, RF, "The Preparation is Described of Bimodal Dispersions by Blending Monomodal Polymer Dispersions Having Different Particle Sizes." DE-A3,036,969

13. Moayed, SH, Fatemi, S, Pourmahdian, S, "Synthesis of a Latex with Bimodal Particle Size Distribution for Coating Applications Using Acrylic Monomers." Prog. Org. Coat., 60 (4) 312-319 (2007)

14. Piirma, I, Chang, M, "Emulsion Polymerization of Styrene: Nucleation Studies with Nonionic Emulsifier." J. Polym. Sci.: Polym. Chem. Ed., 20 489-498 (1982)

15. Boutti, S, Graillat, C, McKenna, TF, "High Solids Content Emulsion Polymerisation Without Intermediate Seeds. Part II. In Situ Generation of Bimodal Lattices.' Polymer, 46 (4 Spec. Iss.) 1211-1222 (2005)

16. Peters, ACIA, Overbeek, GC, Annable, T, "Bimodal Particle Size Distribution Polymer/Oligomer Combinations for Printing Ink Applications." Prog. Org. Coat., 38 (3) 137$150(2000)$

17. Blum, H, Höhlein, P, Meixner, J, "Water-Thinnable, Saponification Resistant Binders." Eur. Coat. J., 8-13 (1989)

18. Tomba, JP, Xiaodong, Y, Li, Fugang, Winnik, MA, Lau, W, "Polymer Blend Latex Films: Miscibility and Polymer Diffusion Studied by Energy Transfer." Polymer, 49 (8) 2055-2064 (2008)

19. Verkholantsev, VV, "Self-Stratifying Coatings for Industrial Applications.' Pigment Resin Technol., 32 (5) 300-306 (2003)

20. Urban, MW, “Why Coatings Stratify?” Eur. Coat. J., 1-2 36 (2003)

21. Smith, GA, Boucher, SP, Grinstein, RH, "Latex for HeatResistant Inks.' US Patent 5,373,045, 1994; Heinz-Hilmar, B, Gyopar, RM, Karl-Heinz, S, "Process for Preparation of Emulsifier-Free Polymer Dispersions.” EP 511520, 1992; Heinz-Hilmar, B, Gyopar, RM, Karl-Heinz, S, "Process for Preparation of Emulsifier-Free Polymer Dispersions." DE 4113839, 1992; Feustel, D, Meyer, M, Hoefer, R, Oberkobusch, D, Fristad, WE, "Oligomeric Carboxylic 
Acids as Stabilizers for Emulsion Polymerization." DE 4026640, 1992; Ely, JK, "Fast Drying Water Inks." EP 360212, 1990

22. Schlarb, B, Haremza, S, Heckmann, W, Morrison, B, Müller-Mall, R, Rau, MG, "Hydroresin Dispersions: Tailoring Morphology of Latex Particles and Films." Prog. Org. Coat., 29 (14) 201-208 (1996)

23. Satgurunathan, R, Roelands, M, van Ginkel, M, "A Polyurethane and Vinyl Polymer Based Recyclable Aqueous Coating Composition." EP 1694733, 2006

24. Tang, J, Daniels, ES, Dimonie, VL, Vratsanos, MS, Klein, A, El-Aasser, MS, "Mechanical Properties of Films Prepared from Model High-Glass-Transition-Temperature/Low-Glass-Transition-Temperature Latex Blends." J. Appl. Polym. Sci., 86 (11) 2788-2801 (2002)

25. Kivilevich, A, "A Paradigm Shift: The New Role of Heterogeneity and Interactions." J. Coat. Technol., 1 (4) 38-48 (2004)

26. Vidovska, D, Maurer, FHJ, "Tensile Properties and Interfacial Interactions of Bimodal Hard/Soft Latex Blends." Compos. Interfaces, 13 (8-9) 819-830 (2006)

27. Feng, J, Winnik, MA, Shivers, RR, Clubb, B, "Polymer Blend Latex Films: Morphology and Transparency." Macromolecules, 28 (23) 7671-7682 (1995)

28. He, Y, Zhu, B, Inoue, Y, "Hydrogen Bonds in Polymer Blends." Prog. Polym. Sci., 29 1021-1051 (2004)

29. Keddie, JL, Meredith, P, Jones, RAL, Donald, AM, “Film Formation of Acrylic Latices with Varying Concentrations of Non-Film-Forming Latex Particles." Langmuir, 123793 3801 (1996)

30. Utrack, LA, Walsh, DJ, Weiss, RA, "Polymer Alloys, Blends and Ionomers." ACS Symp. Ser., 395 1-38 (1989)

31. Overbeek, A, Bückmann, F, Martin, E, Steenwinkel, P, Annable, T, "New Generation Decorative Paint Technology." Prog. Org. Coat., 48 (2-4) 125-139 (2003)

32. Beetsma, J, "Alkyd Emulsion Paints: Properties, Challenges and Solutions." Pigment Resin Technol., 27 (1) 12-19 (1998)

33. Overbeek, A, Bückmann, F, Tennebroek, R, Bouman, J, "New Generation Decorative Paint Technology." Macromol. Symp., 187 (1) 187-198 (2002)

34. Martin, E, Overbeek, GC, Steenwinkel, P, Tennebroek, R, "Aqueous Hyperbranched Macromolecule Coating Compositions." US Patent 7,094,826, 2006; Buckmann, AJP, Martin, E, Overbeek, GC, Padget, JC, Scheerder, J, Annable, T, "Aqueous Vinyl Polymer Coating Compositions." US Patent 7,223,813, 2007; Buckmann, AJP, Martin, E, Overbeek, GC, Padget, JC, Scheerder, J, Annable, T, "Aqueous Polyester Coating Compositions." US Patent 7,022,759, 2007

35. Overbeek, A, Bückmann, F, Martin, E, Steenwinkel, P, Annable, T, Athens Conference on Coatings Science and Technology, pp. 199-216 (2002)

36. Tuck, N, Waterborne and Solvent Based Alkyds and Their End User Applications. Wiley/Sita Series in Surface Coatings Technology, Vol. VI, p. 277. Wiley, London, ISBN 471985910

37. Walsh, DJ, Booth, C, Price, C (eds.), Comprehensive Polymer Science, Vol. 2, p. 135. Pergamon, Oxford (1989)

38. Flick, EW, Water-Based Paint Formulations, Vol. 4. Elsevier (1998), ISBN-13: 978-0-8155-1415-2

39. Pianoforte, K, Coatings World, February 2005

40. Dieterich, D, "Aqueous Emulsions, Dispersions and Solutions of Polyurethanes; Synthesis and Properties." Prog. Org. Coat., 9 (3) 281-340 (1981)

41. van de Wiel, H, Zom, W, "Waterborne Acrylics and Urethanes for the Coatings Industry." JOCCA, 64 (7) 263 (1981)
42. Okamoto, Y, Hasegawa, Y, Yoshino, F, "Urethane/Acrylic Composite Polymer Emulsions." Prog. Org. Coat., 29175 (1996)

43. Overbeek, GC, Heuts, MPJ, "Polyurethane Coating Compositions." US Patent 4,983,662, 1991

44. Wang, C, Chu, F, Guyot, A, Gauthier, C, Boisson, F, "Hybrid Acrylic-Polyurethane Latexes: Emulsion versus Miniemulsion Polymerisation." J. Appl. Polym. Sci., 101 (6) 3927-3941 (2006)

45. Guyot, A, Landfester, K, Schork, FJ, Wang, C, "Hybrid Polymer Latexes." Prog. Polym. Sci., 32 1439-1461 (2007)

46. Sperling, LH, Introduction to Physical Polymer Science, p. 667. John Wiley \& Sons, Inc, Hoboken, NJ (2006), ISBN 0-471-70606-X

47. Durant, YG, Sundberg, DC, "Latex Particle MorphologyFundamental Aspects: A Review." Polym. React. Eng., 11 (3) 379-432 (2003)

48. Sundberg, DC, Casassa, AP, Pantozopoulos, J, Muscato, MR, "Morphology Development of Polymeric Microparticles in Aqueous Dispersions. I. Thermodynamic Considerations." J. Appl. Polym. Sci., 411425 (1990)

49. Dimonie, VL, El-Aasser, MS, Vanderhoff, JW, Polym. Mater. Sci. Eng., 58821 (1988)

50. Winzor, CL, Sundberg, DC, "Conversion Dependent Morphology Predictions for Composite Emulsion Polymers: 1. Synthetic Lattices." Polymer, 33 (18) 3797-3810 (1992)

51. Stubbs, JM, Sundberg, DC, "Nonequilibrium Particle Morphology Development in Seeded Emulsion Polymerization. III. Effect of Initiator End Groups."' J. Appl. Polym. Sci., 91 (3) 1538-1551 (2004)

52. Stubbs, JM, Sundberg, DC, "The Dynamics of Morphology Development in Multiphase Latex Particles." Prog. Org. Coat., 61 156-165 (2008)

53. Lee, S, Rudin, A, "Effects of Surfactants and Polymerization Methods on the Morphology of Particles Formed in 'Core-Shell' Emulsion Polymerization of Methyl Methacrylate and Styrene." Macromol. Rapid Commun., 10 655661 (1989)

54. Jönsson, J-EL, Hassander, H, Jansson, LH, Törnell, B, "Morphology of Two-Phase Polystyrene/Poly(Methyl Methacrylate) Latex Particles Prepared Under Different Polymerization Conditions." Macromolecules, 24 (1) 126131 (1991)

55. Karlsson, LE, Karlsson, OJ, Sundberg, DC, "Nonequilibrium Particle Morphology Development in Seeded Emulsion Polymerization. II. Influence of Seed Polymer Tg." J. Appl. Polym. Sci., 90 (4) 905-915 (2003)

56. Heuts, M, LeFebre, R, Hilst, LV, Overbeek, G, "Influence of Morphology on Film Formation of Acrylic Dispersions." Proc. PMSE Symposium on Latex Film Formation, Chicago, IL (1995)

57. Devon, MJ, Gardon, JL, Roberts, GRA, "Effects of CoreShell Latex Morphology on Film Forming Behavior." J. Appl. Polym. Sci., 39 (10) 2119-2128 (1990)

58. Coogan, RG, Vartan-Boghossian, R, "Aqueous Dispersions." US Patent 4,927,876, 1990; Goos, HC, Overbeek, GC, "Aqueous Dispersions." US Patent 5,137,961, 1992; Overbeek, GC, Heuts, MPJ, "Polyurethane Coating Compositions." US Patent 4,983,662, 1991; Petschke, G, Yang, S, "Urethane-Acrylic Hybrid Polymer Dispersion." US Patent 6,635,706, 2003; Yang, S, Petschke, G, "Air Curable Water-Borne Urethane-Acrylic Hybrids." US Patent $6,239,209,2001$

59. Hu, YS, Tao, Y, Hu, CP, “Polyurethaneurea/Vinyl Polymer Hybrid Aqueous Dispersions Based on Renewable Material." Biomacromolecules, 2 (1) 80-84 (2001) 
60. Pan, H, Chen, D, "A Strategy for Preparation of Anionic Polyurethane/Acrylate Emulsions." Polym. Plast. Technol. Eng., 47 (6) 595-599 (2008)

61. Zhu, X, Jiang, X, Zhang, Z, Kong, XZ, "Influence of Ingredients in Water-Based Polyurethane-Acrylic Hybrid Latexes on Latex Properties." Prog. Org. Coat., 62 (3) 251257 (2008)

62. Satguru, G, McMahon, J, Padget, JC, Coogan, R, “Aqueous Polyurethanes-Polymer with Unusual Colloidal, Morphological and Application Characteristics." Proceedings of the Waterborne, High-Solids, and Powder Coatings, Symposium, New Orleans (1993)

63. Chao, J, Zhang, XY, Dai, JB, Ge, Z, Feng, LL, "Synthesis of a Novel Core-Shell Type Acrylic-Polyurethane Hybrid Emulsion Containing Siloxane and Fluorine as well as Water and the Oil Resistances of Cured Film." Chin. Chem. Lett., 17 (8) 1121-1124 (2006)

64. Šebenik, U, Krajnc, M, "Properties of Acrylic-Polyurethane Hybrid Emulsions Synthesized by the Semibatch Emulsion Copolymerization of Acrylates Using Different Polyurethane Particles." J. Polym. Sci. A: Polym. Chem., 43 (18) 4050-4069 (2005)

65. Hirose, M, Kadowaki, F, Zhou, J, "The Structure and Properties of Core-Shell Type Acrylic-Polyurethane Hybrid Aqueous Emulsions." Prog. Org. Coat., 31 (12) 157-169 (1997)

66. Dong, A, Feng, S, Sun, D, “Structure-Property Relationships of Core-Shell Type Waterborne Polyacrylate-Polyurethane Microemulsions." Macromol. Chem. Phys., 199 (12) 2635-2640 (1998)

67. Šebenik, U, Golob, J, Krajnc, M, "Comparison of Properties of Acrylic-Polyurethane Hybrid Emulsions Prepared by Batch and Semibatch Processes with Monomer Emulsion Feed." Polym. Int., 52 (5) 740-748 (2003)

68. Kim, IH, Shin, JS, Cheong, IW, Kim, JI, Kim, JH, "Seeded Emulsion Polymerization of Methyl Methacrylate Using Aqueous Polyurethane Dispersion: Effect of Hard Segment on Grafting Efficiency." Colloids Surf. A: Physicochem. Eng. Aspects, 207 (1-3) 169-176 (2002)

69. Hegedus, CR, Kloiber, KA, "Aqueous Acrylic-Polyurethane Hybrid Dispersion and Their Use in Industrial Coatings." J. Coat. Technol., 860 39-48 (1996)

70. Kukanja, D, Golob, J, Zupancic-Valant, A, Krainc, MJ, "The Structure and Properties of Acrylic-Polyurethane Hybrid Emulsions and Comparison with Physical Blends." J. Appl. Polym. Sci., 78 67-80 (2000)

71. Brown, RA, Coogan, GC, Fortier, DG, Reeve, MS, Rega, JD, "Comparing and Contrasting the Properties of Urethane/Acrylic Hybrids with those of Corresponding Blends of Urethane Dispersions and Acrylic Emulsions." Prog. Org. Coat., 5273 (2005)

72. Wang, C, Chu, F, Guyot, A, "Mechanical Properties of Films from Hybrid Acrylic-Polyurethane Polymer Colloids." J. Dispers. Sci. Technol., 27 325-330 (2006)

73. Tsavalas, JG, Gooch, JW, Schork, FJ, "Water-Based Crosslinkable Coatings via Miniemulsion Polymerization of Acrylic Monomers in the Presence of Unsaturated Polyester Resin." J. Appl. Polym. Sci., 75 (7) 916-927 (2000)

74. Turpin, ET, "Hydrolysis of Water-Dispersible Resins." J. Paint Technol., 47 (602), 40-46 (1975)

75. Bender, ML, Chloupek, F, Neveu, MC, “Intramolecular Catalysis of Hydrolytic Reactions. III. Intramolecular Catalysis by Carboxylate Ion in the Hydrolysis of Methyl Hydrogen Phthalate." J. Am. Chem. Soc., 80 (20) 53845387 (1958)
76. O’Neill, G, Rothwell, AR, “Hair Grooming Method Using Linear Polyesters." US Patent 4,300,580, Eastman Kodak Company, 1981

77. Geurink, PJA, Scherer, T, Buter, R, Steenbergen, A, Henderiks, H, "A Complete New Design for Waterborne 2-Pack PUR Coatings with Robust Application Properties." Prog. Org. Coat., 55 (2) 119-127 (2006)

78. Blount, WW, "Water-Dissipatable Polyester Resins and Coatings Prepared Therefrom." US Patent 4,910,292, 1990; US Patent 4,973,656, 1990; US Patent 4,990,593, 1991

79. Clark, MD, Phan, HD, Salisbury, JR, Shields, GD, "Small Particle Size Polyester/Acrylic Hybrid Latexes.' US Patent 6,001,922, 1999

80. Anderson, JL, Pekarik, AJ, Tokas, E, "Polymeric Compositions, and the Preparation and Use Thereof." WO9924485, 1999; Anderson, JL, Pekarik, AJ, Tokas, E, "Polymeric Compositions, and the Preparation and Use Thereof." EP1030889, 2000; Anderson, JL, Pekarik, AJ, Tokas, E, "Polymeric Compositions, and the Preparation and Use Thereof." US Patent 6,894,117, 2004

81. Shimizu, T, Higashiura, S, Ohguchi, M, Murase, H, Akitomo, Y, "Water-Borne Polyester for Inks and Coatings: Structural Elucidation of Acrylic-Grafted Polyester and the Particle of Its Aqueous Dispersion." Polym. Adv. Technol., 10 446-454 (1999)

82. Schork, FJ, Tsavalas, J, "The Morphology of Alkyd/ Acrylate Latexes Produced via Hybrid Miniemulsion Polymerization: Grafting Mechanisms." Prog. Colloid Polym. Sci., 124 126-130 (2003)

83. Nabuurs, T, "Alkyd-Acrylic Composite Emulsions. Polymerization and Morphology." $\mathrm{PhD}$ Thesis, Eindhoven University of Technology (1997)

84. Schork, FJ, Bechtold, N, Tiarks, F, Antonietti, M, "Waterborne Alkyd Coatings by Miniemulsion Polymerization." US Patent 6,369,135, 1999

85. Dong, H, Gooch, JW, Schork, FJ, "Waterborne OilModified Polyurethane Coatings via Hybrid Miniemulsion Polymerization." J. Appl. Polym. Sci., 76105 (2000)

86. van Hamersveld, E, van Es, J, Cuperus, FP, "Oil Acrylate Hybrid Emulsions, Mini-Emulsion Polymerization and Characterization." Colloid Surf. A: Physicochem. Eng. Aspects, 153285 (1999)

87. Shoaf, GL, Stockl, RR, "Alkyd/Acrylic Hybrid Latexes with Enhanced Oxidative Curing." Polym. React. Eng., 11 (3) 319-334 (2003)

88. Zueckert, B, "Process for Producing Improved Alkyd Resin Emulsions.” US Patent 4,333,864, 1982; Zueckert, B, "Aqueous Emulsion of Air Drying and Stoving Alkyd Resins and Process for Producing Said Resins." US Patent 4,333,865, 1982; Zueckert, B, Awad, R, Weger, W, "WaterDilutable Brushing Paint Based on Water-Soluble Alkyd Resins." US Patent 6,489,398, 2002; Awad, R, Dworak, G, Zueckert, B, Weger, W, "Water-Dilutable Air-Drying Protective Coating Compositions." US Patent 4,996,250, 1991; Billiani, J, Gobec, M, "Process for the Preparation of Water-Dilutable Air-Drying Coating Binders, and the Use Thereof." US Patent 5,698,625, 1997

89. Zuckert, B, "Aqueous Emulsion of Air Drying and Stoving Alkyd Resins and Process for Producing Said Resins.' US Patent 4,333,865, 1982

90. Landfester, K, Pawelzik, U, Antonietti, M, "Polydimethylsiloxane Latexes and Copolymers by Polymerization and Polyaddition in Miniemulsion." Polymer, 46 (23) 9892-9898 (2005)

91. Kong, XZ, Ruckenstein, E, "Core-Shell Latex Particles Consisting of Polysiloxane-Poly(Styrene-Methyl 
Methacrylate-Acrylic Acid): Preparation and Pore Generation." J. Appl. Polym. Sci., 73 2235-2245 (1999)

92. Kan, CY, Zhu, XL, Yuan, Q, Kong, XZ, "Graft Emulsion Copolymerization of Acrylates and Siloxane." Polym. Adv. Technol., 8 631-633 (1997)

93. Pan, G, Wu, L, Zhang, Z, Li, D, "Synthesis and Characterization of Epoxy-Acrylate Composite Latex." J. Appl. Polym. Sci., 83 (8) 1736-1743 (2002)

94. De Wet-Roos, D, Knoetze, JH, Cooray, B, Sanderson, RD, "Emulsion Polymerization of an Epoxy-Acrylate Emulsion Stabilized with Polyacrylate. I. Influence of Salt, Initiator, Neutralizing Amine, and Stirring Speed." J. Appl. Polym. Sci., 71 (8) 1347-1360 (1999)

95. Li, S-X, Wang, W-F, Liu, L-M, Liu, G-Y, "Morphology and Characterization of Epoxy-Acrylate Composite Particles." Polym. Bull., 61 (6) 749-757 (2008)

96. Hanrahan, K, Wood, KA, Hedhli, L, Gupta, RR, Skilton, W, "Highly Weatherable Roof Coatings Containing Aqueous Fluoropolymer Dispersions." WIPO Patent Application $\mathrm{WO} / 2007 / 030152,2007$

97. Jeong, P, Dimonie, VL, Daniels, ES, El-Aasser, MS, "Hybrid Composite Latexes." ACS Symp. Ser., 801 357$373(2002)$

98. ASTM D4946-89, "Standard Test Method for Blocking Resistance of Architectural Paints." ASTM, Philadelphia, PA (2008)

99. Bückmann, F, Overbeek, A, Nabuurs, T, "Self-Crosslinking Surfactant Free Acrylic Dispersions." Eur. Coat. J., 6 53-60 (2001)

100. Tamai, T, Wanatabe, M, “Acrylic Polymer/Silica Hybrids Prepared by Emulsifier-Free Emulsion Polymerization and the Sol-Gel Process." J. Polym. Sci. A: Polym. Chem., 44 273-280 (2006)

101. Tiarks, F, Landfester, K, Antonietti, M, "Silica Nanoparticles as Surfactants and Fillers for Latexes Made by Miniemulsion Polymerization." Langmuir, 17 (19) 5775$5780(2001)$

102. Zhou, J, Zhang, S, Qiao, X, Wu, LJ, "Controlled Growth of One-Dimensional Oxide Nanomaterials." Polym. Sci. A: Polym. Chem., 443202 (2006)

103. Percy, MJ, Armes, SP, "Surfactant-Free Synthesis of Colloidal Poly (Methyl Methacrylate)/Silica Nanocomposites." Langmuir, 184562 (2002)

104. Wanatabe, M, Tamai, T, “Acrylic Polymer/Silica OrganicInorganic Hybrid Emulsions for Coating Materials: Role of the Silane Coupling Agent." J. Polym. Sci. A: Polym. Chem., 44 4736-4742 (2006)

105. Nobel, ML, Picken, SJ, Mendes, E, "Waterborne Nanocomposite Resins for Automotive Coating Applications." Prog. Org. Coat., 58 (23) 96-104 (2007)

106. Diaconu, G, Paulis, M, Leiza, JR, “Towards the Synthesis of High Solids Content Waterborne Poly(Methyl Methacrylate-co-Butyl Acrylate)/Montmorillonite Nanocomposites." Polymer, 49 (10) 2444-2454 (2008)

107. Ruggerone, R, Plummer, CJG, Herrera, NN, BourgeatLami, E, Månson, J-AE, "Highly Filled Polystyrene Laponite Nanocomposites Prepared by Emulsion Polymerization." Eur. Polym. J., 45 (3) 621-629 (2009)

108. Wei, W, Zhang, C, Ding, S, Qu, X, Liu, J, Yang, Z, "Template Synthesis of Hydrogel Composite Hollow Spheres Against Polymeric Hollow Latex." Colloid Polym. Sci., 286 (89) 881-888 (2008)

109. Arfsten, NJ, Armes, S, Buskens, PJP, Thies, JC, Vrijaldenhoven, PWA, "Core Shell Nanoparticles." $\mathrm{WO} / 2008 / 028640$
110. Webster, OW, "Living Polymerization Methods." Science, 251 (4996) 887-893 (1991)

111. Bon, SAF, Ohno, K, Haddleton, DM, "Water-Soluble and Water Dispersible Polymers by Living Radical Polymerization." ACS Symp. Ser., 780 148-161 (2001)

112. Haddleton, DMEJ, Kukulj, D, Morsley, SM, Steward, AG, "Aqueous Solution Cobalt Mediated Catalytic Chain Transfer Polymerization." Polym. Preprints (ACS Div. Polym. Chem.), 40 (1) 381-382 (1999)

113. Suddaby, KG, Haddleton, DM, Hastings, JJ, Richards, SN, O'Donnell, JP, "Catalytic Chain Transfer for Molecular Weight Control in the Emulsion Polymerization of Methyl Methacrylate and Methyl Methacrylate-Styrene." Macromolecules, 29 (25) 8083-8091 (1996)

114. Huybrechts, J, Bruylants, P, Vaes, A, De Marre, A, "Surfactant-Free Emulsions for Waterborne, Two-Component Polyurethane Coatings." Prog. Org. Coat., 38 (2) 67-77 (2000)

115. Hawker, CJ, Bosman, AW, Harth, E, "New Polymer Synthesis by Nitroxide Mediated Living Radical Polymerizations." Chem. Rev., 101 (12) 3661-3688 (2001)

116. Matyjaszewski, K, Xia, J, "Atom Transfer Radical Polymerization.” Chem. Rev., 101 (9) 2921-2990 (2001)

117. Chiefari, J, Chong, YK, Ercole, F, Krstina, J, Jeffery, J, Le, TPT, Mayadunne, RTA, Thang, SH, "Living Free-Radical Polymerization by Reversible Addition-Fragmentation Chain Transfer: The RAFT Process." Macromolecules, 31 (16) 5559-5562 (1998)

118. Chong, YK, Moad, G, Rizzardo, E, Thang, SH, “Thiocarbonylthio End Group Removal from RAFT-Synthesized Polymers by Radical-Induced Reduction." Macromolecules, 40 4446-4455 (2007)

119. Odian, G, Principles of Polymerization, 4th edn., p. 329. John Wiley and Sons, New York. ISBN 0471274003,9780471274001

120. Perrier, S, Takolpuckdee, P, Mars, CA, "Reversible AdditionFragmentation Chain Transfer Polymerization: End Group Modification for Functionalized Polymers and Chain Transfer Agent Recovery." Macromolecules, 38 2033-2036 (2005)

121. Barner-Kowollik, C (ed.), Handbook of RAFT Polymerization. Wiley-VCH, Weinheim (2008)

122. Burguiere, C, Pascual, S, Coutin, B, Polton, A, Tardi, M, Charleux, B, Matyjaszewski, K, Vairon, J-P, “Amphiphilic Block Copolymers Prepared via Controlled Radical Polymerization as Surfactants for Emulsion Polymerization." Macromol. Symp., 150 39-44 (2000)

123. Lecolley, F, Waterson, C, Carmichael, AJ, Mantovani, G, Harrisson, S, Chappell, H, Limer, A, Williams, P, Ohno, K, Haddleton, DM, "Synthesis of Functional Polymers by Living Radical Polymerization." J. Mater. Chem., 13 (11) 2689-2695 (2003)

124. Spinelli, HJ, "Group Transfer Polymerization and Its Use in Water Based Pigment Dispersants and Emulsion Stabilizers." Prog. Org. Coat., 27 (1-4) 255-260 (1996)

125. Rosthauser, JW, Nachtkamp, K, "Waterborne Polyurethanes." J. Coat. Fabr., 16 39-79 (1986)

126. Sung, CSP, Smith, TW, Sung, NH, "Properties of Segmented Polyether Poly(Urethaneureas) Based on 2, 4Toluene Diisocyanate. 2. Infrared and Mechanical Studies." Macromolecules, 13 117-121 (1980)

127. Wang, CB, Cooper, SL, "Morphology and Properties of Segmented Polyether Polyurethane Ureas." Macromolecules, 16 775-786 (1983)

128. Allport, DC, "Polyamides and Polyureas from 2,2'- and 4,4'-Bipiperidines." Monograph, 25 143-159 (1967)

129. Narrainen, AP, Pascual, S, Haddleton, DM, “Amphiphilic Diblock, Triblock, and Star Block Copolymers by Living 
Radical Polymerization: Synthesis and Aggregation Behavior." J. Polym. Sci. A: Polym. Chem., 40 (4) 439-450 (2002)

130. Wicks, DA, Wicks, ZW, Jr, "Autoxidizable Urethane Resins." Prog. Org. Coat., 54 (3) 141-149 (2005)

131. Ehrlich, A, Patton, TC, Franco, A, "Viscosity Profiles of Solvent Based Paints: Their Measurement and Interpretation.” J. Paint Technol., 45 (576) 58-67 (1973)
132. Patton, TC, Paint Flow and Pigment Dispersion, 2nd edn., p. 554. John Wiley and Sons, New York, ISBN 0-471-032727 (1979)

133. Oosterlinck, F, Steenwinkel, P, Tennebroek, R, Steeman, P, "Waterborne Coatings-Body Building Studied." Eur. Coat. J., 3 96-119 (2009) 